\title{
Modelling of landslides in a scree slope induced by groundwater and rainfall
}

\author{
Daisy Lucas MSC \\ Doctoral Researcher, Institute of Geotechnical Engineering, ETH Zürich, \\ Zürich, Switzerland (corresponding author: daisy.lucas@igt.baug.ethz.ch) \\ Ralf Herzog Dipl. Ing. \\ Head of Laboratory, Institute of Geotechnical Engineering, ETH Zürich, \\ Zürich, Switzerland \\ Markus Iten Mech. Techn. \\ Head Technician (Centrifuge), Institute of Geotechnical Engineering, \\ ETH Zürich, Zürich, Switzerland \\ Heinz Buschor Mech. Techn. \\ Design Technician (Workshop), Institute of Geotechnical Engineering, \\ ETH Zürich, Zürich, Switzerland
}

Predicting the trigger of a slope failure of a steep Alpine scree slope in south-west Switzerland is challenging. The groundwater (GW) flow from snow-melting and rainfall infiltration during summer changes the susceptibility to surficial failure, which also depends on the slope angle, bedrock geometry, stratigraphy and the shear strength of the soil. Surficial failure mechanisms are investigated using prototype ground models that integrate input from field monitoring, geological observations and soil properties and account for relevant factors and constraints for physical and numerical modelling. Shallow scree deposits overlying various bedrock configurations (parallel to the slope, with and without a step) were tested under two hydrological regimes: GW flow, and GW combined with additional intense rainfall. Numerical modelling was used to study the parameter combinations that would lead to failure, and worst-case scenarios were defined in terms of the bedrock geometry and hydraulic perturbations. These results were verified using advanced physical modelling techniques in a geotechnical drum centrifuge. Physical modelling results indicated that, for a given GW condition, slope stability decreases (a) as the depth of the soil cover over the bedrock decreases and $(b)$ the higher the bedrock step. Furthermore, a bedrock step impacts the volume and the location of the triggered failure. Rainfall exacerbates the situation.

\begin{tabular}{ll}
\multicolumn{2}{l}{ Notation } \\
$c^{\prime}$ & cohesion \\
$h$ & soil thickness \\
$N$ & scaling factor in the centrifuge \\
$p^{\prime}$ & mean effective stress $\left(2 \sigma_{3}^{\prime}+\sigma_{1}^{\prime}\right) / 3$ \\
$Q$ & input flow rate \\
$q$ & deviatoric stress $\left(\sigma_{1}^{\prime}-\sigma_{3}^{\prime}\right)$ \\
$X_{1}$ & top length of bedrock step \\
$X_{2}$ & length base of bedrock step \\
$y$ & height of bedrock step \\
$\sigma_{1}^{\prime}$ & axial effective stress \\
$\sigma_{3}^{\prime}$ & lateral effective stress \\
$\phi^{\prime}$ & angle of internal friction
\end{tabular}

\section{Introduction}

A project was developed by ETH Zürich in collaboration with the Agarn community, Canton Wallis, Switzerland to quantify the hazard associated with the surficial failure of an extensive north-facing Alpine scree slope in the Meretschibach catchment (Lucas et al., 2017; Springman et al., 2015). The 33-43 inclined scree slope (Figure 1(a)) is located at the top of the mountain slope (1840-1910 m a.s.l. (metres above sea level)), next to a highly eroded debris-flow channel path, which collects a portion of mobilised soil and rock debris, 'harvested' from above and from the neighbouring slopes. The potential source of material, which could accumulate prior to triggering as a debris flow, could eventually reach the community of Agarn (620 m a.s.1.), located downstream of the eroded channel bed, in more extreme cases (Frank et al., 2017; Lucas et al., 2017; Oggier, 2011). The dynamics and growing changes in the geomorphology of the catchment may imply new hazards in terms of slope instability in the future, and therefore it is important to understand when and how the slope could fail, and what the triggers would be.

The stratigraphy of the slope was characterised (Lucas et al., 2017) and a ground model was defined (Figure 1(b)) for use in the physical and numerical simulations. A field monitoring campaign reported by Lucas et al. (2017), was carried out over a duration of 3 years, with instrumentation installed to record temperature, volumetric water content (VWC), suction and precipitation (additional information is provided in the paper by Lucas et al. (2017) and in the online supplementary material). 


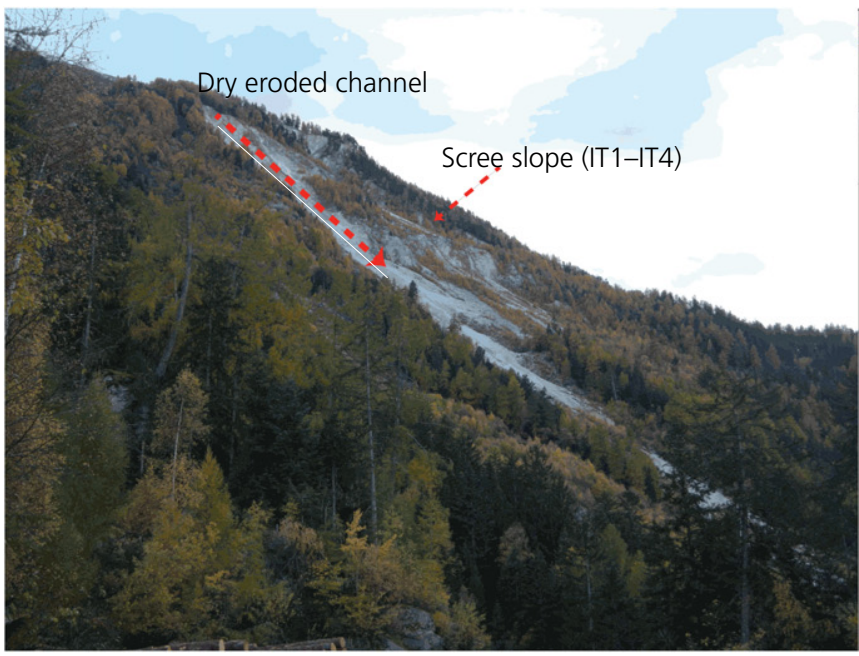

(a)

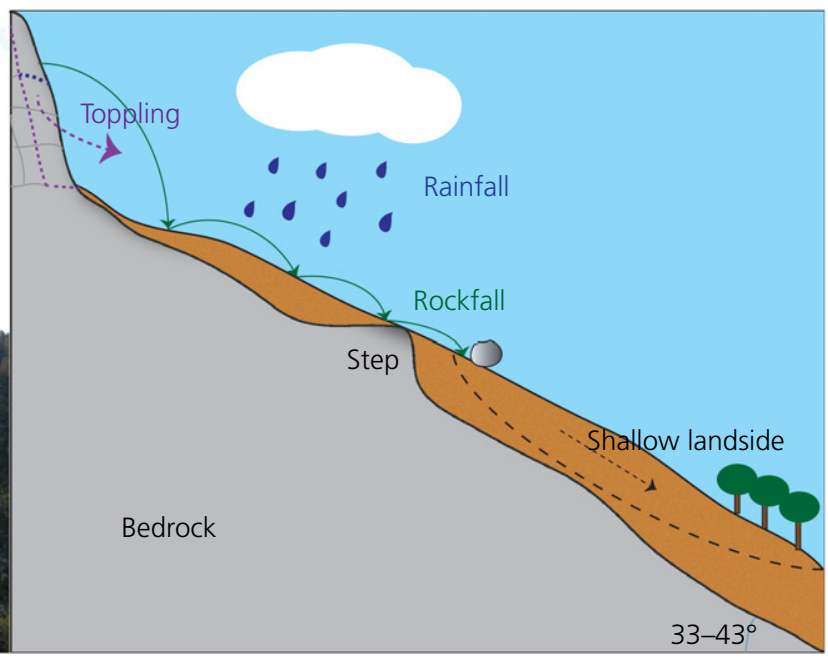

(b)

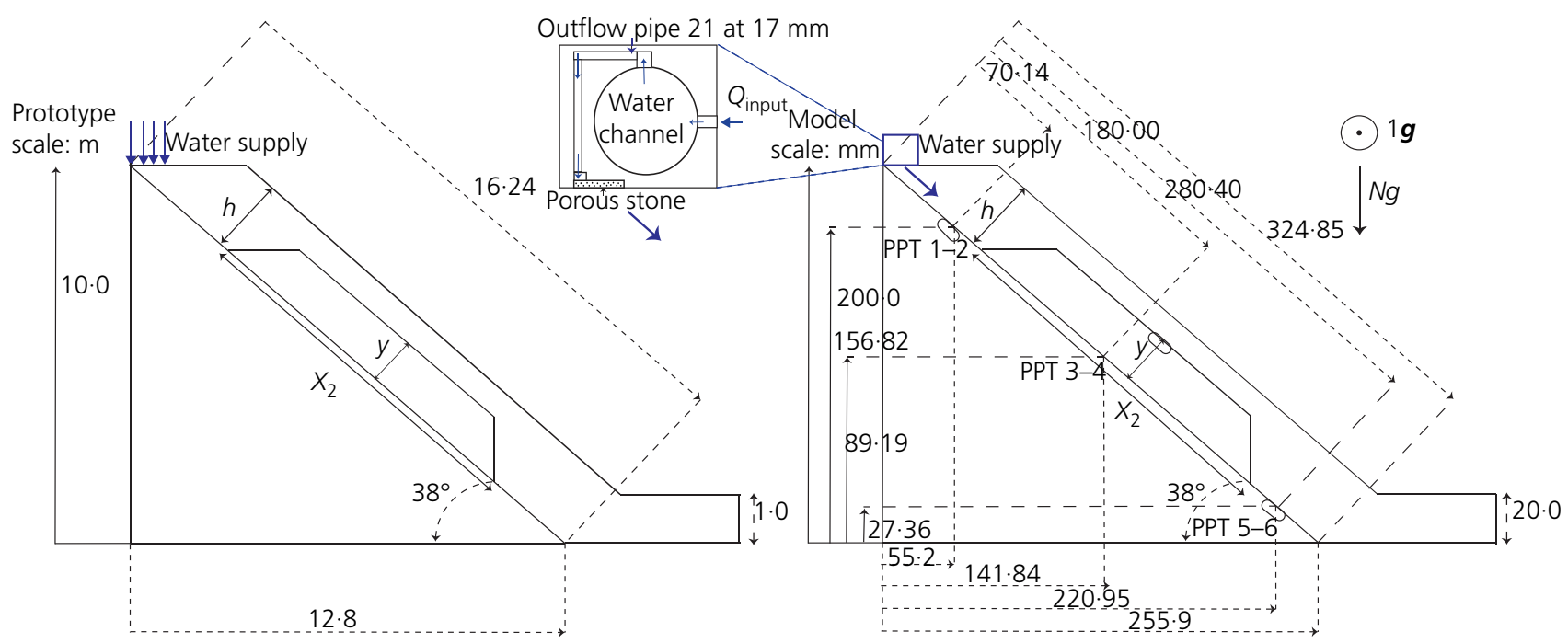

(c)

(d)

Figure 1. Scree slope in the Meretschibach catchment, Bochtür area: (a) scree slope and dry eroded debris flow channel, (b) simplified schematic ground model, (c) prototype and numerical model in metres and (d) scaled centrifuge physical model in millimetres.

The direction of the Earth's gravity acts out of the paper towards the reader. IT, instrumented soil trench; PPT, pore pressure transducer.

These data sets were complemented by a series of triaxial stress path tests in the laboratory on reconstituted specimens extracted from sampling in test pits in the slope, and were combined with geophysical measurement techniques (electrical resistivity tomography (ERT), ground penetrating radar (GPR)) to determine the depth of bedrock (Fankhauser, 2014).

It was confirmed that the degree of saturation in an Alpine scree slope at Meretschibach is strongly related to the seasonal weather changes (Lucas et al., 2017). The slope is subjected to precipitation in the form of snow in winter, when temperatures are negative or near zero, which provides insulation against variations in the local air temperature and prevents significant changes in the VWC. The temperature increases in spring and the snow-melt infiltrates into the ground. Additional precipitation can be in the form of snow or rain, due to daily temperature variations. Finally, rainfall precipitation in summer increases the soil saturation, hence decreasing suction and effective stress in the soil.

The soil became fully saturated only in one location (of the four investigated) in a coarser layer at $1 \mathrm{~m}$ depth, after a 
period of intense rainfall (Lucas et al., 2017). This reinforces a hypothesis that the most unfavourable conditions for the slope stability could be very local and occur in spring-summer time, when rainfall infiltration combined with groundwater (GW) flow from snow-melting reduces the effective stress and hence the shear strength of the soil.

Additionally, a series of bedrock strata at the soil-bedrock interface, inclined southwards with a $10-30^{\circ}$ dip (Gabus et al., 2008a, 2008b), were identified from geological observations as outcrops or 'steps' in the bedrock above the ground, which are expected to affect the local slope stability (Lucas et al., 2017).

Based on the reported information of field monitoring, laboratory testing and geological observation, it was predicted that a scree saturated above a steeply inclined shallow bedrock could become unstable. Furthermore, should there be a step in the bedrock that outcrops at the surface, failure would occur upslope of the outcrop, depending on step geometry (height/ length). A slope failure was thought less likely to happen if the bedrock was parallel to the slope with no bedrock step, albeit that the lower part of the slope would then be more endangered, where GW could emerge at the surface (Take and Beddoe, 2014). Intermediate cases would be determined by the height $(y)$ and length of a step in the bedrock $\left(X_{2}\right)$, and would lie between these two failure mechanisms, which should be explored through physical and numerical modelling.

The hypothesis was explored using a ground model that integrates findings from field monitoring and data from laboratory testing, by varying soil thickness and bedrock step geometry. Numerical simulations were conducted first in two dimensions, using Seep-Slope/W software from GeoStudio (Krahn, 2004a, 2004b) to analyse key influences. These were then investigated in the subsequent physical modelling programme, in which a plane prototype geometry and model soil were tested in parametric analyses under $50-52 \mathrm{~g}$ in the ETH geotechnical drum centrifuge (Springman et al., 2001). The results show convincing evidence of the effect of the bedrock step geometry on the landslide triggering and the respective mechanisms of failure.

\section{Methodology}

The physical and numerical modelling are complementary and allow different aspects to be investigated using parametric analyses. The centrifuge modelling captures

- cracking and failure initiation (moment of mobilisation of soil and water as the debris runs out)

- timing and run-out (to be considered with respect to scaling effects)

- transient pore water pressure (PWP) processes, derived from GW flow and rainfall in three dimensions (3D).
The numerical model represents

- idealisation as a decoupled steady-state analysis of flow, combined with

- a simplified two-dimensional (2D) analysis of state at failure of homogeneous, rigid-perfectly plastic soil

- and it does not consider transient behaviour, pre-failure deformations, three-dimensional (3D) influences (on flow or failure) or the effects of tensile cracking on macro-permeability, form of the failure surface or a variable and/or strain-dependent shear resistance mobilised along a failure surface and so on.

This is important, on one hand, because the rigid-perfectly plastic soil response, modelled in the slip surface analysis is generally considered to be conservative, given that the contributions of the side shear surfaces to the total shear resistance are not included. This is why it can be argued that it is an acceptable approximation (e.g. Askarinejad et al., 2012; Springman et al., 2003). On the other hand, creating opportunities for water to ingress easily through tension cracks to greater depth causes rapid saturation and potentially swifter 'fluidisation' of the failing landmass with reduced shear strength, leading to earlier failure, a different form of the failed mass and most likely a far greater run-out. This is more risky for inhabitants living below such a failing slope.

Therefore, running both types of analyses allows a richer understanding to be obtained of the response of a slope to GW flow combined with rainfall. Furthermore, checks can be made on whether there are secondary or tertiary effects that will change the expected behaviour considerably.

Two types of hydrological regimes were applied in numerical models, followed by a series of 17 centrifuge model tests (Table 1), in which soil thicknesses and bedrock step geometry were varied. Slope stability under GW flow released at the top of the slope was investigated initially, followed by an antecedent of GW flow combined with intense rainfall.

A variety of cases were run in the numerical simulations, which helped to select critical combinations of soil thickness and bedrock step geometry. These were then studied in the centrifuge tests to identify slope failure triggering mechanisms.

Centrifuge technology has been used for slope stability analysis since the 1960s (Taylor, 1995). The challenge of trying to represent a prototype slope with a small model has confronted many researchers over the years, often through the establishment of a reference model, with appropriate stress history and heterogeneity in the slope. Increasing radius, measured from the centrifuge axis, from top to bottom of the slope affects the nominal $\boldsymbol{g}$-level imposed on the model, leading to challenging 
Table 1. Programme for the numerical simulations (those chosen for centrifuge testing are in bold)

\begin{tabular}{|c|c|c|c|c|c|c|c|}
\hline Test & Name of test & $\begin{array}{l}\text { Soil thickness } \\
h: m\end{array}$ & $\begin{array}{l}\text { Bedrock step } \\
\text { height, } y: m\end{array}$ & $y / h: m$ & $\begin{array}{l}\text { Bedrock step } \\
\text { length, } X_{2}: m\end{array}$ & $\begin{array}{l}\text { Ground model } \\
\text { figure }\end{array}$ & Centrifuge test descriptor \\
\hline 1 & GP_1.0_0_0 & 1.0 & 0 & 0 & 0 & & \\
\hline 2 & GP_1.0_0.25_8.5 & $1 \cdot 0$ & 0.25 & 0.25 & 8.5 & & \\
\hline 3 & GP_1.0_0.5_8.5 & $1 \cdot 0$ & 0.5 & 0.5 & 8.5 & & \\
\hline 4 & GP_1.0_0.6_8.5 & 1.0 & 0.6 & 0.6 & $8 \cdot 5$ & & \\
\hline 5 & GP_1.0_0.75_8.5 & 1.0 & 0.75 & 0.75 & 8.5 & & 4.a (Figure S24) \\
\hline 6 & GP 1.2500 & $1 \cdot 25$ & 0 & 0 & 0 & & 8.b (Figure S28) \\
\hline 7 & GP_1.25_0.25_3 & $1 \cdot 25$ & $0 \cdot 31$ & 0.25 & $3 \cdot 0$ & & \\
\hline 8 & GP_1.25_0.5_3 & $1 \cdot 25$ & 0.63 & 0.5 & $3 \cdot 0$ & & \\
\hline 9 & GP_1.25_0.6_3 & $1 \cdot 25$ & 0.75 & 0.6 & $3 \cdot 0$ & & 7.b (Figure S27) \\
\hline 10 & GP_1.25_0.75_3 & 1.25 & 0.94 & 0.75 & $3 \cdot 0$ & & \\
\hline 11 & GP_1.25_0.25_8.5 & 1.25 & $0 \cdot 31$ & 0.25 & $8 \cdot 5$ & & \\
\hline 12 & GP_1.25_0.5_8.5 & 1.25 & 0.63 & 0.5 & $8 \cdot 5$ & & \\
\hline 13 & GP_1.25_0.6_8.5 & $1 \cdot 25$ & 0.75 & 0.6 & $8 \cdot 5$ & & 7.a, 8.a (Figure 15) \\
\hline 14 & $\mathrm{GP} \quad 1.25 \quad 0.75 \quad 8.5$ & $1 \cdot 25$ & 0.94 & 0.75 & $8 \cdot 5$ & & \\
\hline 15 & GP_1.5_0_0 & $1 \cdot 5$ & 0 & 0 & 0 & 6(a) & 1.b, 6.b (Figure 12) \\
\hline 16 & GP_1.5_0.25_3 & 1.5 & 0.38 & 0.25 & $3 \cdot 0$ & $5(a), 6(b)$ & \\
\hline 17 & GP_1.5_0.5_3 & 1.5 & 0.75 & 0.5 & $3 \cdot 0$ & $5(b), 6(c)$ & 5.b (Figure S25) \\
\hline 18 & GP_1.5_0.75_3 & 1.5 & $1 \cdot 125$ & 0.75 & $3 \cdot 0$ & $5(c), 6(d)$ & 2.b, 3.b, 4.b (Figure 13, S23) \\
\hline 19 & GP_1.5_0.25_8.5 & 1.5 & 0.38 & 0.25 & $8 \cdot 5$ & $5(d), 6(e)$ & \\
\hline 20 & GP_1.5_0.5_8.5 & 1.5 & 0.75 & 0.5 & $8 \cdot 5$ & $5(e), 6(f)$ & 2.a, 3.a (Figure S22) \\
\hline 21 & GP_1.5_0.75_8.5 & 1.5 & $1 \cdot 125$ & 0.75 & 8.5 & $5(f), 6(g)$ & 1.a, 5.a, Proof. (Figure 14, S21) \\
\hline 22 & $\mathrm{GP} 3.000$ & $3 \cdot 0$ & 0 & 0 & 0 & $6(h)$ & \\
\hline 23 & GP_3.0_0.25_8.5 & $3 \cdot 0$ & 0.75 & 0.25 & 8.5 & $6(i)$ & \\
\hline 24 & GP_3.0_0.375_8.5 & $3 \cdot 0$ & $1 \cdot 125$ & 0.375 & $8 \cdot 5$ & $5(g)$ & 6.a (Figure S26) \\
\hline 25 & GP_3.0_0.5_8.5 & $3 \cdot 0$ & 1.5 & 0.5 & $8 \cdot 5$ & $6(j)$ & \\
\hline 26 & GP_3.0_0.75_8.5 & $3 \cdot 0$ & $2 \cdot 25$ & 0.75 & 8.5 & $6(k)$ & \\
\hline
\end{tabular}

testing conditions (Bryant et al., 2015; Park, 2013; Schofield, 1980). Recent results on the simulation of landslides induced by rainfall using centrifuge technology have been promising (Askarinejad, 2013; Askarinejad et al., 2014a, 2014b; Craig, 2014; Lee and Bolton, 2006; Ling and Ling, 2012; Schofield, 1978; Take, 2014; Take and Beddoe, 2014; Timpong et al., 2007). However, there are still challenges in modelling such events in a geotechnical centrifuge. This contribution offers some additional original ideas and solutions.

\subsection{Test soil properties}

The scree slope (Figure 2, Table 2) is mainly a silty gravel (GP-GM) with <10\% fines (Lucas et al., 2017). The field soil grain size distribution (GSD) (Figure 2) is an average of gradings obtained from samples from four instrumented trenches (IT1-4). There were less fines in the gravel at higher locations (1900 m a.s.1.), as shown for IT3 (GP) (Figure 2). The critical state angle of friction of the soil was determined as $41^{\circ}$ from constant shear drained (CSD) stress path tests on reconstituted specimens at an equivalent relative density of $41-59 \%$ (Grob, 2015).

The 'scaled soil' grading is $\approx 1 / 50$ th of the prototype soil (for centrifuge tests performed at $50 \mathrm{~g}$ ), to maintain the grainsize-structural element dimensional ratio in the small-scale

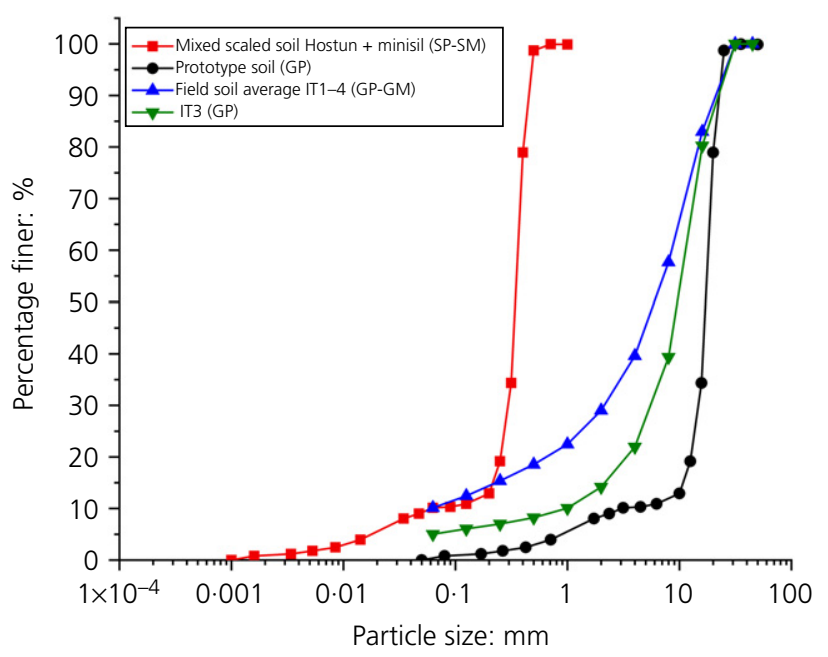

Figure 2. GSDs: average grading curve for field gravel from IT1-IT4 (GP-GM) and gravel IT3 (GP), silty sand mixed scaled soil (SP-SM); prototype gravelly soil (GP)

model - that is, the bedrock steps and the overall dimensions of the strong box should not influence the model slope response due to unwanted particle-size effects. 
Table 2. Properties of field gravel (GP-GM), mixed scaled soil (SP-SM) and scaled up again at $50 \mathbf{g}$ (GP)

\begin{tabular}{|c|c|c|c|}
\hline Property & Field soil (GP-GM) & Mixed scaled soil (SP-SM) & Prototype mixed (GP) \\
\hline$e_{\max }$ & 0.690 & 0.899 & - \\
\hline$e_{\min }$ & $0 \cdot 340$ & 0.609 & - \\
\hline$D_{50}: \mathrm{mm}$ & $6 \cdot 400$ & 0.345 & $17 \cdot 300$ \\
\hline$D_{10}: \mathrm{mm}$ & 0.065 & 0.060 & 3.000 \\
\hline$C_{u}\left(D_{60} / D_{10}\right)$ & $138 \cdot 4$ & $6 \cdot 0$ & $6 \cdot 0$ \\
\hline$C_{\mathrm{c}}\left(\left(D_{30}^{2} / D_{10}\right) D_{60}\right)$ & $9 \cdot 0$ & $4 \cdot 2$ & $4 \cdot 2$ \\
\hline$G_{s}$ & $2 \cdot 680$ & $2 \cdot 650$ & $2 \cdot 650$ \\
\hline$k: \mathrm{cm} / \mathrm{s}$ & $1.3 \times 10^{-3}(e=0.57)$ & $4.52 \times 10^{-4}(e=0.84)$ & $4.1 \times 10^{-1}(e=0.57)$ \\
\hline Friction angle, $\phi^{\prime}:{ }^{\circ}$ & $41.0^{\mathrm{a}}$ & - & $40.0^{\mathrm{b}}$ \\
\hline Fines content: \% & $9 \cdot 87$ & $10 \cdot 0$ & 0.0 \\
\hline Cohesion, $c^{\prime}: \mathrm{kPa}$ & 0.0 & - & $1.0^{\mathrm{b}}$ \\
\hline Sand content: \% & $18 \cdot 38$ & 90 & $8 \cdot 13$ \\
\hline
\end{tabular}

Notes: e, void ratio; $D_{10}, D_{30}, D_{50}, D_{60}$, soil particle diameter where the $10,30,50$ and $60 \%$ of the sample is finer; $k$, coefficient of permeability from the Kozeny -Carman equation (Carrier, 2003). Void ratio e $=0.57$ average from field data IT1-4 (Lucas et al., 2017)

${ }^{a}$ Derived from triaxial stress path test

balues adopted for numerical modelling

The soil used in the centrifuge tests (mixed scaled soil: Table 2, Figure 2) is a mixture of $90 \%$ Hostun sand (HN31) with $10 \%$ Minisil B1, classified according to Swiss standard classification (SN 670004-2NA) as poorly graded sand with silt (SP-SM). The maximum and minimum void ratios are 0.6 and $0 \cdot 9$, respectively. The matrix soil Hostun sand is angular with a (peak) friction angle of $36^{\circ}$ determined by drained consolidated triaxial testing at a relative density of $73 \%$ and a maximum stress ratio $\left(q / p^{\prime}\right)$ of 1.46 (Alber, 2017). Although the friction angle is lower than the $41^{\circ}$ obtained from the scree on steep slopes up to $43^{\circ}$ inclination, it represents a marginally conservative situation for the model slope, which was set at $38^{\circ}$ (Askarinejad, 2013).

At prototype scale $(\mathrm{Ng})$, the mixed scaled soil reverts to a prototype mixed (GP) (Table 2, Figure 2). Using silty sand for the centrifuge testing allowed a comparison to be made between different model tests in terms of pore-water pressure (PWP) development and failure location, focusing on the failure mechanism due to rain, GW and the effect of stepped bedrock.

\subsection{Model geometry and hydraulic conditions}

The main features of the ground model were provided by Lucas et al. (2017) and were integrated into the physical and numerical models. The model slope angle is $38^{\circ}$, with soil thickness $(h)$ varying between 1 and $3 \mathrm{~m}$ in depth (prototype). A simplified geometry of the step in the bedrock was added with two different values of height $(y)$ and length $\left(X_{2}\right)$ (Figures 1(c) and 1(d), Table 1). The interior angles formed between step-slope bedrock are $36^{\circ}$ (near pore-pressure transducer (PPT) A) and $52^{\circ}$ (near PPT C).

\subsection{Hydraulic regime}

Two GW conditions were implemented

(a) water flow applied at the top of the slope through a hydraulic boundary condition in the numerical model and a porous stone at the base of a water distribution cylinder in the centrifuge (see inset, Figures 1(c) and 1(d); further details are available in the online supplementary material)

(b) rainfall sprinkled above the slope in the centrifuge (see sections 6.2/6.3 in the thesis by Askarinejad (2013)).

Water infiltrates from the top of the slope and seeps nominally parallel to the slope, causing the PWP to rise (a). Additional water infiltrates into the slope through rainfall, to reduce suction enough to trigger a slope failure $((a)$ plus $(b))$.

\section{$2.4 \quad$ Numerical model}

GeoStudio programs Seep/W and Slope/W were used to investigate a variety of scenarios to explore the relevance of soil thickness and bedrock geometry for the assessment of the stability of a steep slope during GW flow. Preliminary results were obtained using an estimated hydraulic conductivity and a saturated/unsaturated model.

The geometry of the numerical model is shown in Figure 1(c). The slope bedrock is of $16 \mathrm{~m}$ length and $10 \mathrm{~m}$ height, with an inclination of $38^{\circ}$. Soil thickness variations are $h=1 \cdot 0,1 \cdot 25$, $1.5,3.0 \mathrm{~m}$. The gravel (GP) properties include $\phi^{\prime}=40^{\circ}$; $c^{\prime}=1 \mathrm{kPa}$ (Table 2, Figure 2), which were selected as representative of the soil used in the centrifuge at prototype scale.

Constant GW flow $(Q)$ was applied from the top of the slope, and the model response was analysed using Seep/W (GeoStudio, 2016), assuming steady-state seepage. The 
International Journal of Physical Modelling in Geotechnics Volume 20 Issue 4
Modelling of landslides in a scree slope induced by groundwater and rainfall

Lucas, Herzog, Iten et al. development of PWP and the location of the GW table provided the parental conditions for the slope stability analysis using Slope/W. 2D limit-equilibrium analysis was performed using the Morgenstern and Price (1965) method, with the slip surface limited to passing through the soil layer.

Numerical modelling explored how the soil thickness $(h)$ and bedrock step geometry (height $(y)$; basal width $\left(X_{2}\right)$ ) affect the global factor of safety (F.S.) for slope stability under steady-state $\mathrm{GW}$ flow. The normalised $\mathrm{GW}$ flow rate $\left(Q_{\text {step }} /\right.$ $\left.Q_{\text {no bedrock step }}\right)$ necessary to trigger failure was plotted as a function of bedrock step height $(y)$ and soil thickness $(h)$ (Figure 1(c)). The stability (F.S.step $/$ F.S. no bedrock step) was also investigated under a specific $\mathrm{GW}$ flow rate $(Q)$ to identify which model geometry was more susceptible to causing a surficial landslide. The detailed testing programme is given in Table 1.

\subsection{Physical model}

The testing programme was carried out in the ETH Zürich geotechnical drum centrifuge (Figure 3 ). The $2.2 \mathrm{~m}$ diameter centrifuge can spin at $600 \mathrm{r} / \mathrm{min}$ to deliver a maximum acceleration of $440 \mathrm{~g}$, testing two diametrically opposed models (models a and b, in Figure 3) simultaneously (Springman et al., 2001).

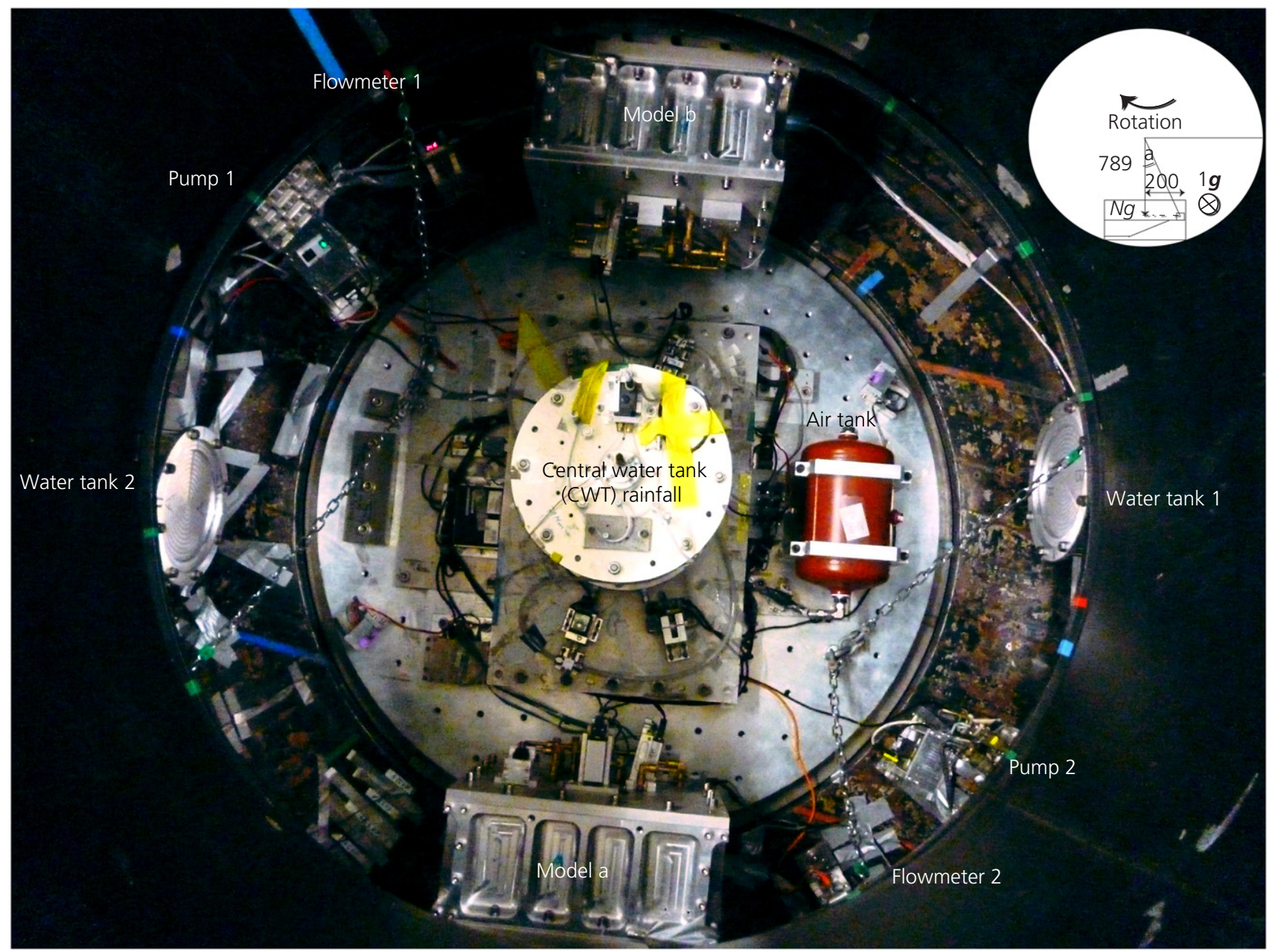

Figure 3. Overview of the set-up in the drum centrifuge, with two models for slope stability, models a and b - only the 'upper box' (climate chamber) is visible in this photograph, the 'lower' boxes (Figure 4(a)) are located behind the 'upper' boxes in the drum flowmeter and pump 2, flowmeter and pump 1, two connected lateral water tanks $(1,2)$ to supply GW flow and the air pressure cylinder. The CWT is located at the centre of the tool platform to supply rain. The dimensions in the sketch (above right) are in $\mathrm{mm}$ 
International Journal of Physical Modelling in Geotechnics Volume 20 Issue 4
Modelling of landslides in a scree slope induced by groundwater and rainfall

Lucas, Herzog, Iten et al.

\subsubsection{Slope geometry and soil characteristics}

Nine different model types were studied in a programme of 17 centrifuge tests (bold in Table 1) to investigate the effects of soil thickness and bedrock step in a scree slope under two hydraulic regimes: GW and GW plus rainfall. The slope geometry is shown in Figures 1(d), 4 and 5, with a slope inclination angle of $38^{\circ}$. The bedrock and steps were made of aluminium and fine sand was sprayed onto a layer of glue to simulate frictional contact. The joints between bedrock slope and steps were sealed with Hylomar $\mathrm{M}$ and are considered impermeable. The soil thicknesses tested in the scaled model were $h=2 \cdot 0,2 \cdot 5,3 \cdot 0$ and $6 \cdot 0 \mathrm{~cm}$ equivalent to $h=1 \cdot 0,1 \cdot 25$, 1.5 and $3 \mathrm{~m}$ at the prototype scale, respectively. All models were provided with a toe berm of $2 \mathrm{~cm}$ (model scale) in height to prevent local erosion. Take and Beddoe (2014) reported that the omission of such a feature would affect, and probably advance, the initiation of failure in some cases.

Soil layers, maximum $2 \mathrm{~cm}$ high, with $5 \%$ moisture content, were tamped to ensure model stability at $1 \boldsymbol{g}$ between model placement in the drum centrifuge (requiring rotation through $90^{\circ}$ ) and testing at $50 \mathrm{~g}$. The slope was cut with an aluminium frame guide and plate, which could be adjusted for different soil layer thicknesses.

The model is contained by an aluminium box of $40 \times 40 \times 20 \mathrm{~cm}$ dimensions (Figure 4), with one poly(methyl methacrylate) (PMMA) side window and two water drainage outlets at the corners. The box is covered by a multi-purpose aluminium box (Figure 3), which contains four to six rain nozzles, either three (model a, Figure 3) or one (model b, Figure 3) photogrammetry camera(s) (Askarinejad et al., 2012), and the newly designed GW distribution system, located at the top of the slope (Figure 1(d)).

The water supply is shown in the inset of Figure 1(d) and represents a cylindrical pipe and a porous stone that runs the width of the model box, whereas the input flow is located in the middle. There are 21 equally spaced outflow pipes (additional information is available in the online supplementary material).

It was a challenge to reproduce a uniform distribution of the GW flow along the top of the slope, due to the radial acceleration in a drum centrifuge with a radius of $<1 \mathrm{~m}$. Several tests were performed with different model orientations and modifications to the set-up to reduce the influence of the radial acceleration field, Coriolis effects and Earth's gravity (Caicedo and Thorel, 2014; Schofield, 1980), which caused water to flow markedly to the model's sides, producing undesirable failures by erosion at the model's edge. The difference in the radius of the model at the top $(0.83 \mathrm{~m})$ and bottom $(1.00 \mathrm{~m})$ of the slope causes a nominal variation in $g$ level from $45 \cdot 1 \mathrm{~g}$ to $54 \cdot 7 \mathrm{~g}$. The component of the Earth's gravity, which acts from the back of the box towards the window, has a significant effect on the flow regime.

The porous stone was inclined to achieve a uniform water flow across the width of the slope, and the bedrock geometry

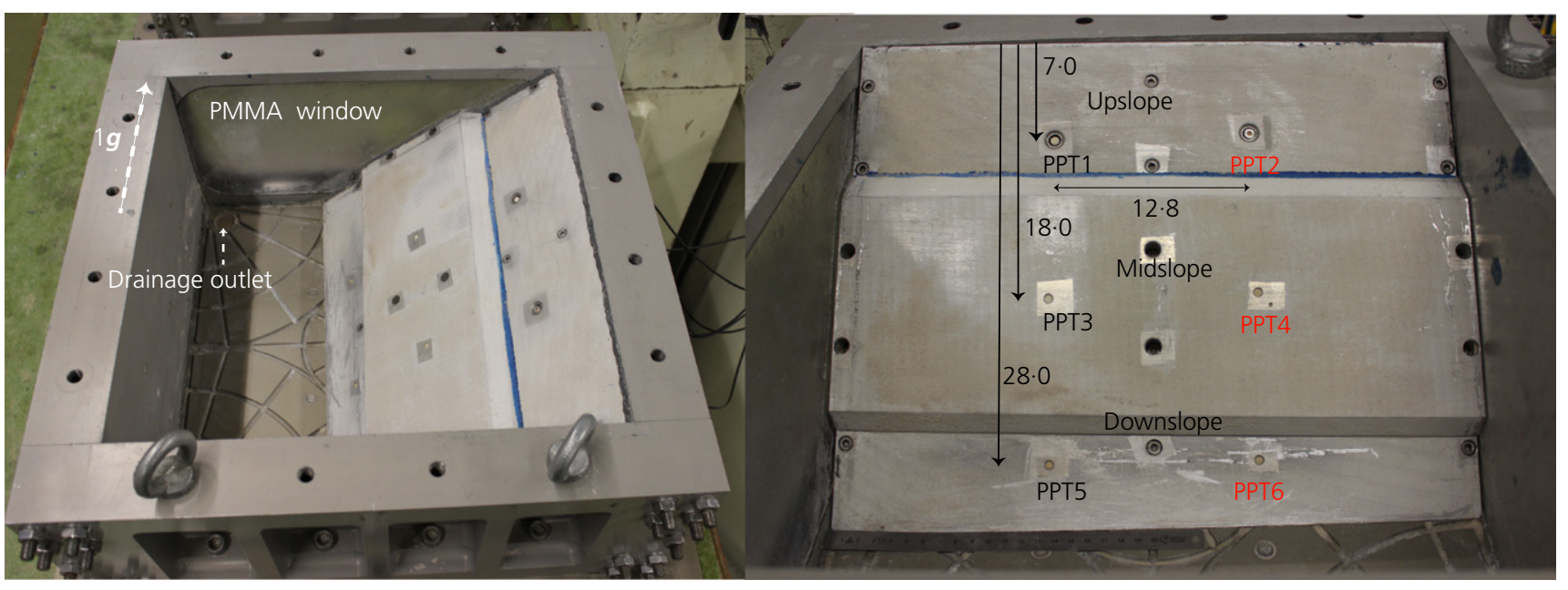

(a)

(b)

Figure 4. (a) Centrifuge model lower box $(40 \times 40 \times 20 \mathrm{~cm})$ with bedrock step and with a poly(methyl methacrylate) (PMMA) window on one side and two water drainage outlets at the base at each corner of the box; (b) bedrock aluminium plate with PPTs and bedrock step. The direction of Earth's gravity acts from the bottom to top in Figure 4(a) and from right to left in Figure 4(b). Distances are in centimetres. Detailed geometry of bedrock and PPT geometry and location are given in the online supplementary material 
was tilted and re-designed as a 3D form (Figure 4), taking the influence of Earth's gravity with increasing distance from the centre of rotation into consideration. All manufacturing was done in-house by the centrifuge and workshop team.

\subsubsection{Set-up in drum centrifuge and instrumentation}

Figure 3 shows the centrifuge set-up, which was adapted to apply the two hydraulic conditions. All devices were designed to operate safely inside the drum at an acceleration of at least $65 \mathrm{~g}$.

The GW flow supply system consisted of an external source of water flowing continuously inside the drum to a perimetral channel at the top of the drum wall (Springman et al., 2001).
The channel was connected to two lateral water tanks (each of 5 litre capacity), so that the inflow was supplied at $1000 \mathrm{ml} / \mathrm{min}$. The two tanks were instrumented with a PPT to monitor water storage and were connected together with a discharge outlet, in case they should overflow at maximum capacity. Water was extracted from each tank and supplied to each model at a predefined rate by a pump (Reglo-Z, Analog Z-140, Ismatec), and was measured by a magneticinductive flow sensor (SM4100). A series of tests was performed to check the pipe diameter (inner diameter $8 \mathrm{~mm}$ ), the water filling system time and refill rates and the calibration of the pumps and flowmeter, which were connected to the centrifuge computer located under the baseplate to the central water tank (CWT) and controlled from the centrifuge control room.

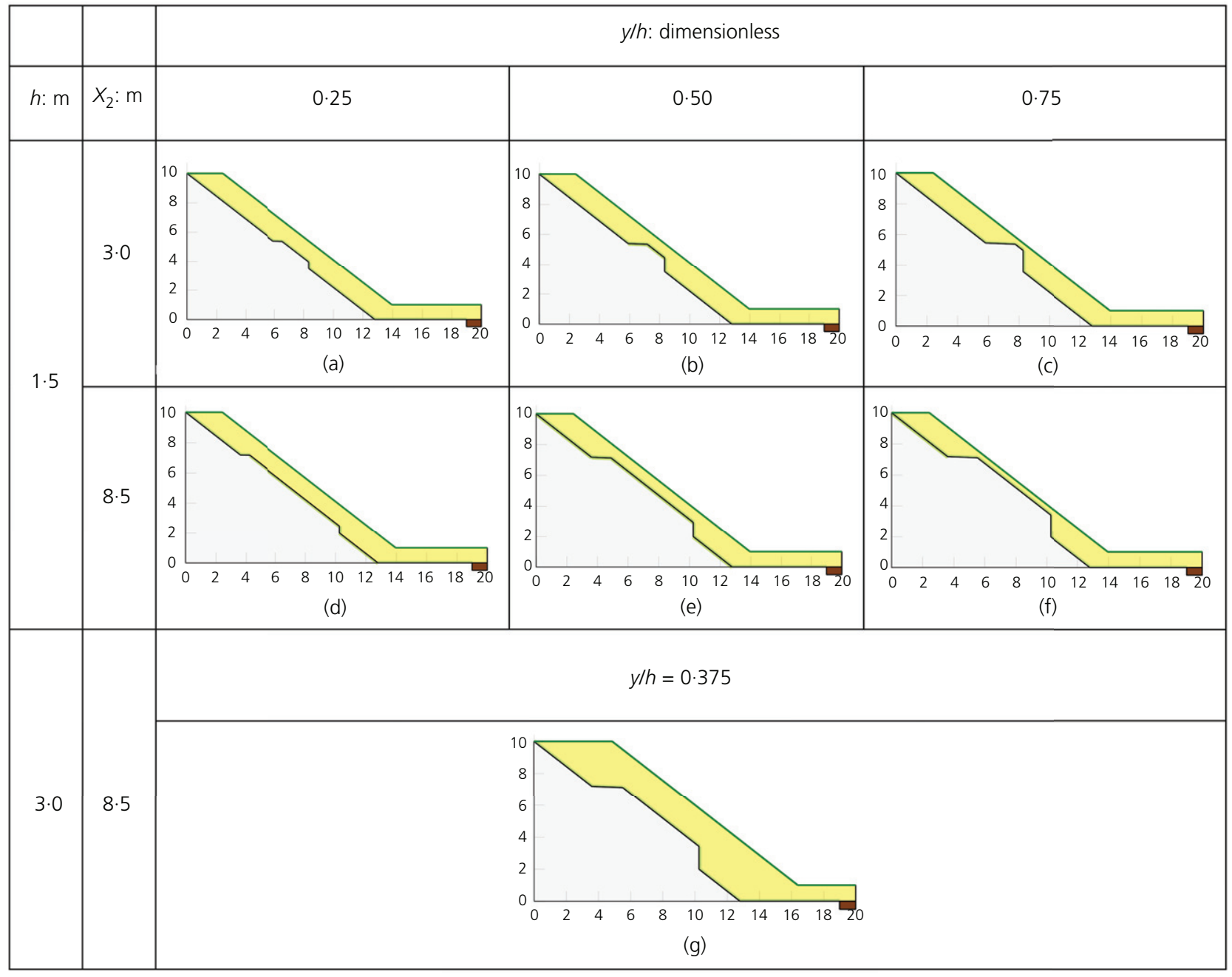

Figure 5. Elevation view of the bedrock and soil layer geometry used in numerical and physical modelling. Slope height is $10 \mathrm{~m}$ and the width of the drawing is $20 \mathrm{~m}$. The drainage outlet is shown in brown at the bottom right of each slope $(h$ is the soil thickness, $y / h$ is the height bedrock step/soil thickness and $X_{2}$ is the length of the bedrock step) 
The rainfall was supplied by a CWT of $24 \cdot 6$ litre capacity, containing water pressurised from an air tank to a maximum of $1000 \mathrm{kPa}$, with an output pressure of $300 \mathrm{kPa}$ (Figure 3). Water was supplied to the inner and outer pipe channels milled in the top plates of the climate chamber (Askarinejad, 2013; Figure 3, for further details see the online supplementary material), and distributed to the nozzles. The rainfall was sprayed into the chamber through aluminium extension tubes of $5-10 \mathrm{~cm}$ in length, so that the rainwater emerged as a spray within a range of $18.9-26.7$ and $13.9-21.7 \mathrm{~cm}$, respectively, above the ground surface. The rain intensity per nozzle was calculated measuring their respective flow $(\mathrm{ml} / \mathrm{min})$ and area, depending at the distance of the nozzle-soil (for further details see the online supplementary material). Assuming that each nozzle rain spray overlapped the soil surface, the total rainfall intensity on the model scale $(\mathrm{mm} / \mathrm{h})$ is estimated as the addition of all intensities. On applying scaling laws, the rain intensity at the prototype was estimated as $N$ times smaller than the model scale (Askarinejad, 2013).

PWP was measured by Druck PDCR81 PPTs and Keller 2Mi (measurement range varying from 35 to $700 \mathrm{kPa}$ ) in six locations at three heights (Figures 1(d) and 4(b)): upstream, on top of and downstream of the bedrock step. The sensors were fitted with porous stones, and saturated and calibrated in the laboratory. Sampling rates were $10 \mathrm{~Hz}$ for model a: PPT1-2, and PPT4, and model b: PPT1-2, PPT4 and PPT6 and $1 \mathrm{~Hz}$ for model a: PPT3-6 and model b: PPT2 -3 and PPT5.

Slope movements were monitored using cameras IDS uEye UI-6240 C with a resolution of 1.3 megapixel. Three cameras were placed in the strongbox lid of model a, and one for model b: each with a sampling rate of $0 \cdot 5-1 \mathrm{~Hz}$.

\section{Results}

\subsection{Numerical modelling}

An overview of all plane-strain failure mechanisms is given in Figures 6(a)-6(k) and will be discussed throughout the following sections. Figures 7(a) and 7(b) show the GW flow rate required to induce failure under two variations of bedrock step geometry: $(a)$ soil thickness $(h)$ and $(b)$ bedrock step length $\left(X_{2}\right)$, with $(y / h)$ as the height of bedrock step normalised by soil thickness (ranging from 0 to $0 \cdot 75$ : Figure 5). The normal-

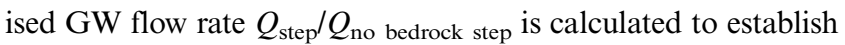
what flow is necessary to induce failure. In both cases, the $Q$ required to cause failure decreases as the size of the bedrock step increases, either with an increase of height or length.

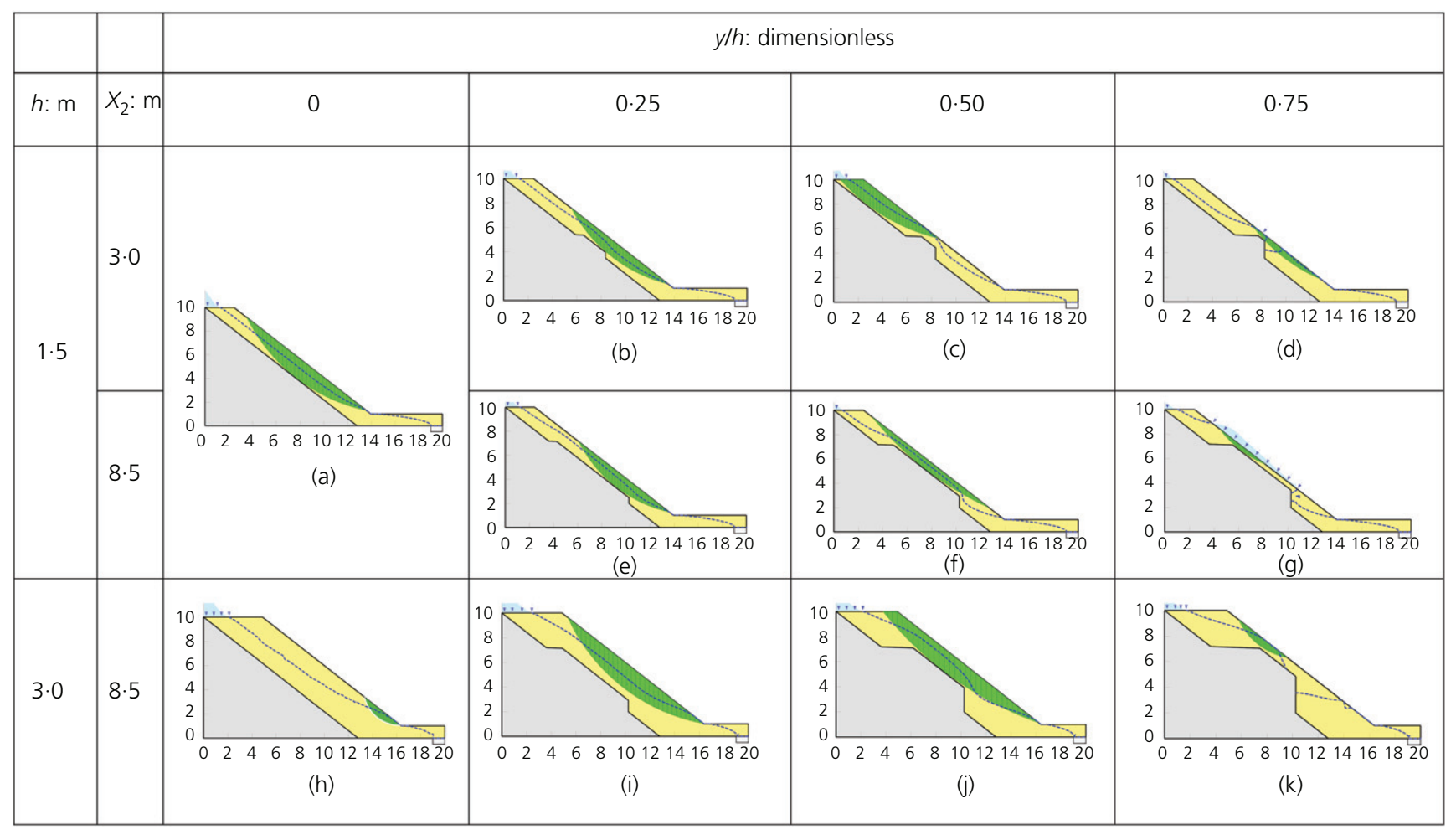

Figure 6. Slip surfaces at failure for numerical simulation with GeoStudio. Hydraulic conditions of GW flow were defined with Seep/W, and slope stability by SlopeN 
Modelling of landslides in a scree slope induced by groundwater and rainfall

Lucas, Herzog, Iten et al.

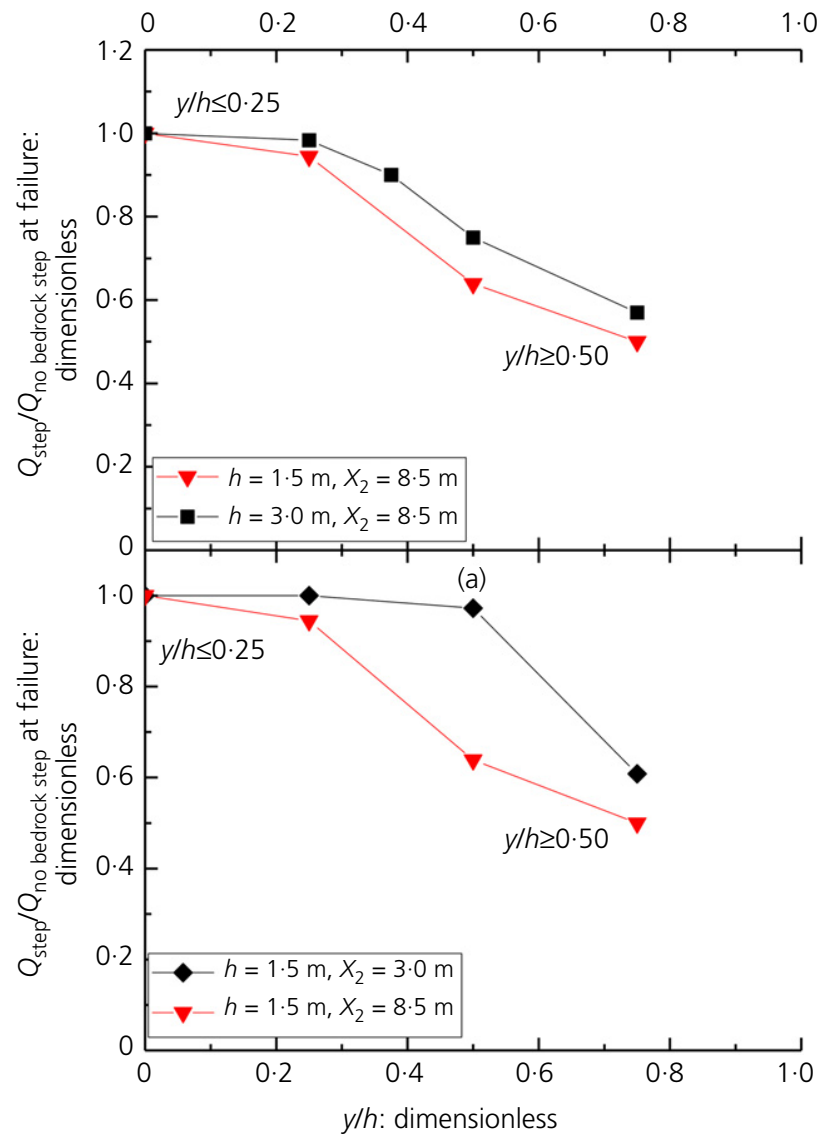

(b)

Figure 7. Numerical modelling: (a) effect of soil thickness and step height $(y / h)$ on the flow rate required for failure, (b) effect of bedrock step length $\left(X_{2}\right)$ on the flow rate required for failure. $Y$ is the height of bedrock step, $h$ is the soil thickness, $Q$ is the GW flow rate

Two soil thicknesses $h=1.5$ and $3.0 \mathrm{~m}$, both representative of field conditions, were compared in Figure 7 (a) for the longest bedrock step $\left(X_{2}=8.5 \mathrm{~m}\right)$. Soil depth variation clearly affects the flow rate required to trigger failure, although the effect is smaller and similar to the case of the slope with no bedrock step $(y / h=0)$, for steps $y / h<0 \cdot 4$. The flow rate required decreases to $\sim 50 \%$ of the case without a bedrock step for $y / h=0 \cdot 75$, for both models with $h=1.5$ and $3 \mathrm{~m}$. The soil above the shorter step was more stable under equivalent flows (Figure 7(b)), as it has less capacity to pond the seepage flow (Figures 6(b), 6(e) and 6(i)).

Figures 8(a) and 8(b) show the effect of bedrock step length $X_{2}$ variation on the normalised $\mathrm{GW}$ flow rate required for slope failure simulation, for $h=1.25$ and $1.5 \mathrm{~m}$. The normalised GW flow rate to trigger failure does not change much for $y / h=0 \cdot 25$ compared to a slope with no bedrock step. The effect of step length is significant when $y / h \geq 0 \cdot 6$, when the required GW flow rate to cause failure is roughly halved. An intermediate response

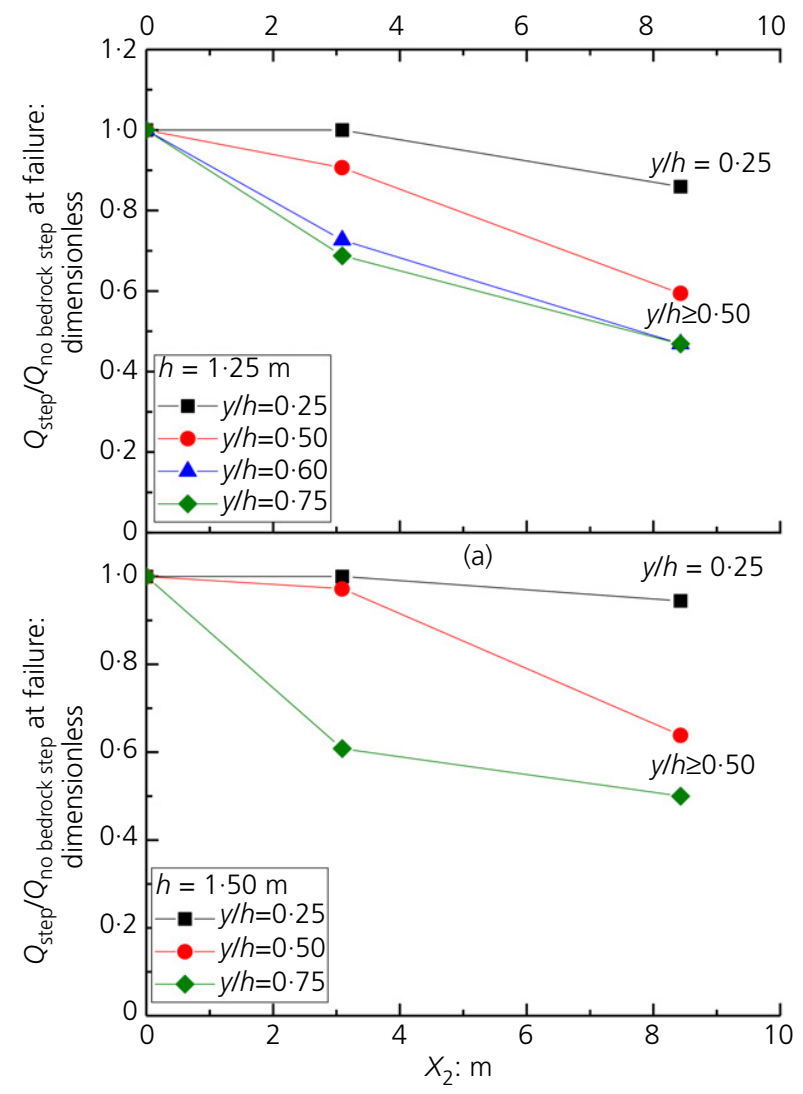

(b)

Figure 8. Effect of bedrock step $(y / h)$ and bedrock length $X_{2}$ against normalised flow rate required for a slope failure for soil thicknesses of (a) $h=1.25 \mathrm{~m}$ and (b) $h=1.5 \mathrm{~m}$

is shown at $y / h=0.5$ for $X_{2}=3.0$ and $8.5 \mathrm{~m}$, whereby significantly higher flow rates, similar to those for $X_{2}=0$, are necessary to cause failure for the shorter step. Soil depth plays a minor role here too, when comparing both depths at $X_{2}=3.0 \mathrm{~m}$. Greatly reduced flows are needed for $y / h \geq 0.6$, for $X_{2}=8.5 \mathrm{~m}$. A longer step can affect the slope stability more during GW flow than a minor change in soil thickness. $Q_{\text {step }} / Q_{\text {no bedrock step at }}$ failure for $0 \cdot 25<y / h \leq 0 \cdot 75$ decreases as the step height $(y)$ increases, while it is similar or equal to 1 for $y / h<0 \cdot 25$.

Figure 9 shows the normalised bedrock step height $(y / h)$

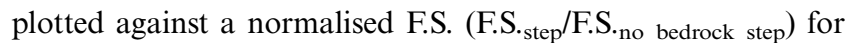
a specific flow rate. The F.S. does not change much for $h<1.5 \mathrm{~m}$ (Figure 9(a)), with a smaller step length of $X_{2}=3 \mathrm{~m}$ (20\% of the length of the slope) and decreases only when $y / h \geq 0 \cdot 5$, typically by $\sim 10 \%$ for the highest step $(y / h=0 \cdot 75)$. The deeper the soil depth, the greater the flow needed to saturate the soil layer upstream of the step to cause instability, whereas water can flow over the short step in the bedrock, reducing the F.S., but again, only by $10 \%$. 
Modelling of landslides in a scree slope induced by groundwater and rainfall Lucas, Herzog, Iten et al.

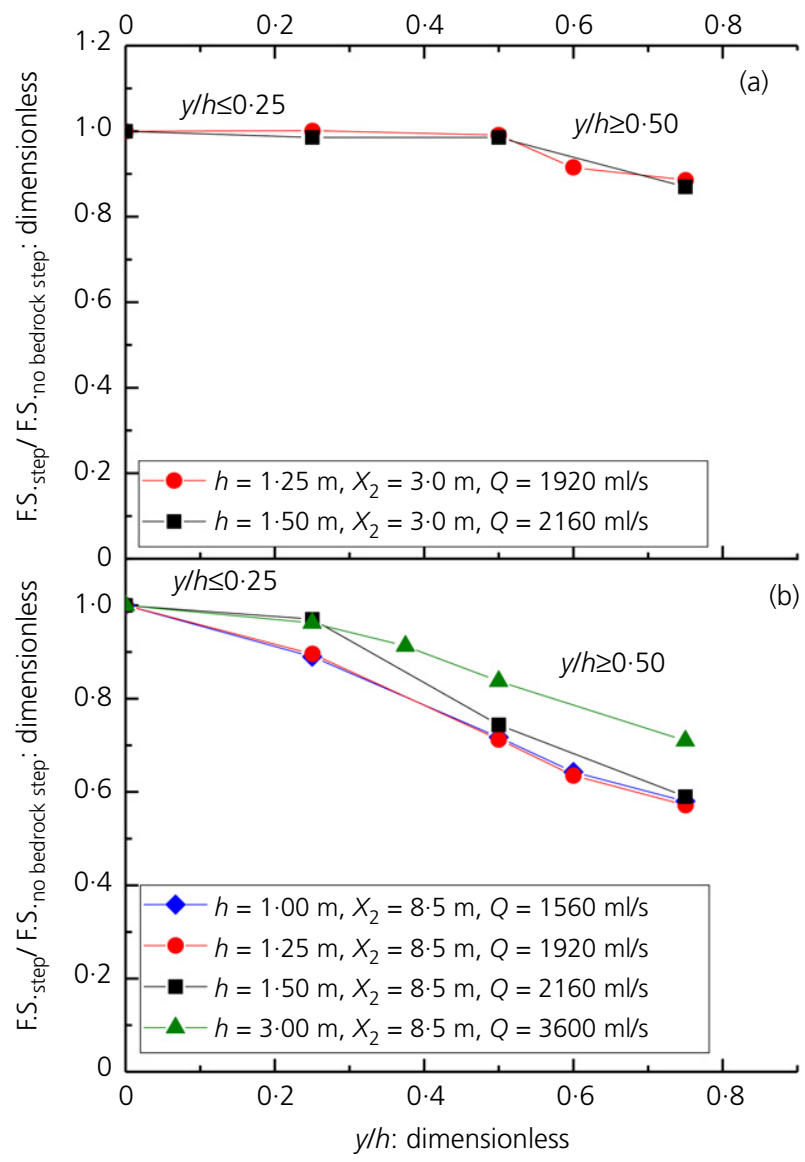

Figure 9. Effect of soil thickness $(h)$ on the normalised F.S. for equal bedrock step length $X_{2}$ and different GW flows: (a) $X_{2}=3 \mathrm{~m}$ and (b) $X_{2}=8.5 \mathrm{~m}$

Four different soil thicknesses are compared in Figure 9(b), all with a defined step length of $X_{2}=8.5 \mathrm{~m}$ : the most unfavourable case in these analyses. A combination of a longer step with a higher step reduces the F.S. of the slope for all soil thicknesses simulated: by $40 \%$ when $h$ is between 1.0 and $1.5 \mathrm{~m}$. F.S. decreases as $y$ increases for a defined flow input $Q$. Likewise (Figure 9), F.S. decreases as $y$ increases and $h$ decreases (Figure 10).

\subsection{Physical modelling}

Selected results from 17 centrifuge tests, performed on nine physical models, with three different soil thicknesses and two different bedrock step geometries (Table 1, Figure 5) are shown in this section. The rest can be found in the online supplementary material. An overview of all failure events is given in Figures 11 (a)-11(h) and will be discussed in the following sections.

Figure 12 shows PWP development against time upslope, midslope and downslope. Each dashed or solid line represents

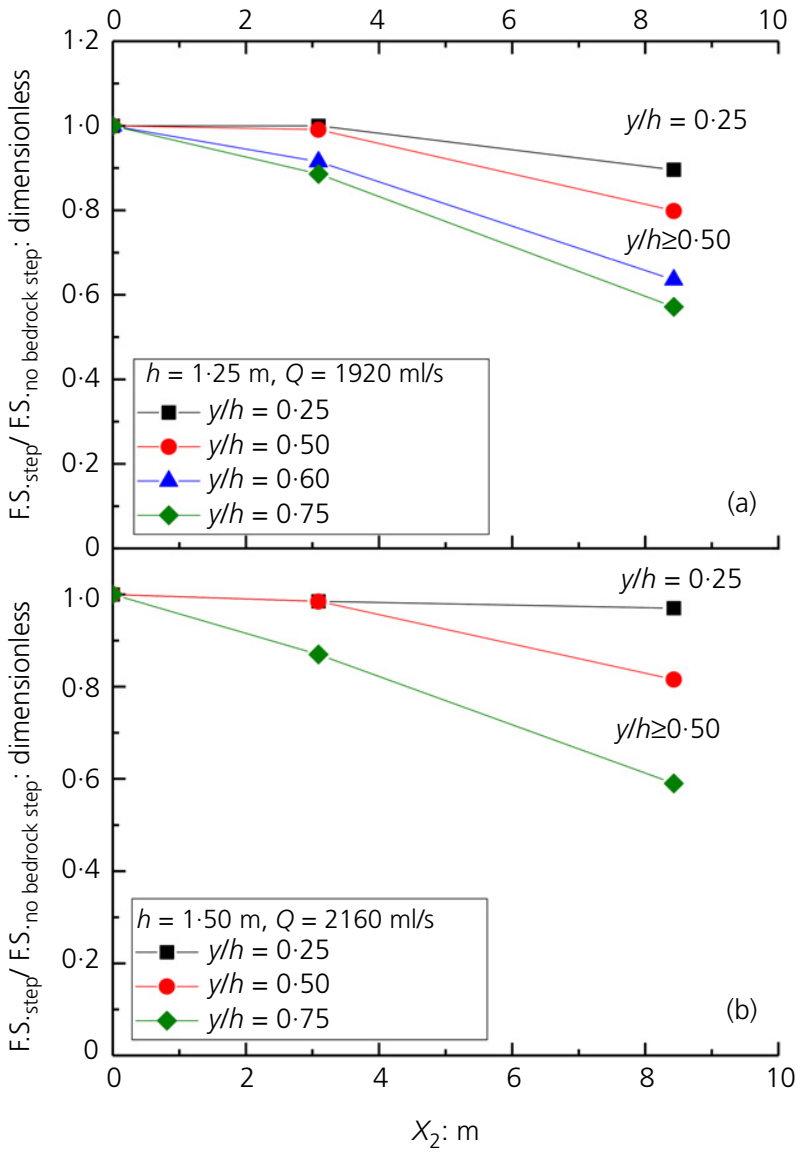

Figure 10. Effect of the length of bedrock step $X_{2}$ on the normalised F.S. for different soil thicknesses and a specific GW flow: (a) for $h=1.25 \mathrm{~m}$ and (b) for $h=1.5 \mathrm{~m}$

a PPT location (Figures 1(d) and 4(b)). The rate of GW flow applied on top of the slope against time (model scale) is given at the bottom. GW and rainfall were combined in some later cycles (Figure 12(b)).

The $Q$ was increased in steps in both tests $1 . \mathrm{b}$ and $6 . \mathrm{b}$ because the tank was refilled after it was emptied at flow rates $>1000 \mathrm{ml} / \mathrm{min}$. The nominal pump capacity was $3290 \mathrm{ml} / \mathrm{min}$ but the maximum flow possible at $50 \mathrm{~g}$ was calibrated at about $2500 \mathrm{ml} / \mathrm{min}$.

PWP sensors at similar elevations show different initial PWP, due either to the model position in the drum at $1 \boldsymbol{g}$ prior to testing or a zero offset reading variation affected by the atmospheric pressure. In addition, despite taking all precautions, it could be due to the marginally incomplete saturation of the porous stone.

The increased PWP in both tests fluctuated between 3 and $7 \cdot 5 \mathrm{kPa}$, with dissipation occurring immediately following the 
Modelling of landslides in a scree slope induced by groundwater and rainfall

Lucas, Herzog, Iten et al. pause in the GW flow, due to the high drainage capacity of the soil. Continuous rain was applied in test $6 . b$ (Figure 12(b)) at $1379 \mathrm{ml} / \mathrm{min}$, equivalent to a rainfall infiltration $215 \mathrm{~mm} / \mathrm{h}$ at model scale and $4.3 \mathrm{~mm} / \mathrm{h}$ in the prototype (Section 2.2; see further details in the online supplementary material). The rainfall helped to increase the pore pressure by an additional $2 \mathrm{kPa}$. Slope failures were not observed in these tests.

Figure 13 shows the effect of a higher $(y / h=0 \cdot 75)$ bedrock step with $X_{2}=3 \mathrm{~m}$. The rise in PWP was similar in test 2.b
(Figure 13(a)) for all PPTs, varying between 2 and $5 \mathrm{kPa}$, and was dissipated swiftly between flow cycles. A failure occurred over the step bedrock $(Q=2500 \mathrm{ml} / \mathrm{min})$, initiated by an increase in PWP at the top junction of the bedrock step and the slope, which produced a tension crack. A small volume was mobilised and bulged over the top of the step, remaining in place for the test duration without any run-out (Figure 11(a)). Increased PWP was between 3 and $5 \mathrm{kPa}$ in the upper slope in test $3 . \mathrm{b}$ and decreased to $2-4 \mathrm{kPa}$ at mid-slope and $1-3 \mathrm{kPa}$ at the bottom. The PWP was slightly higher on the PMMA

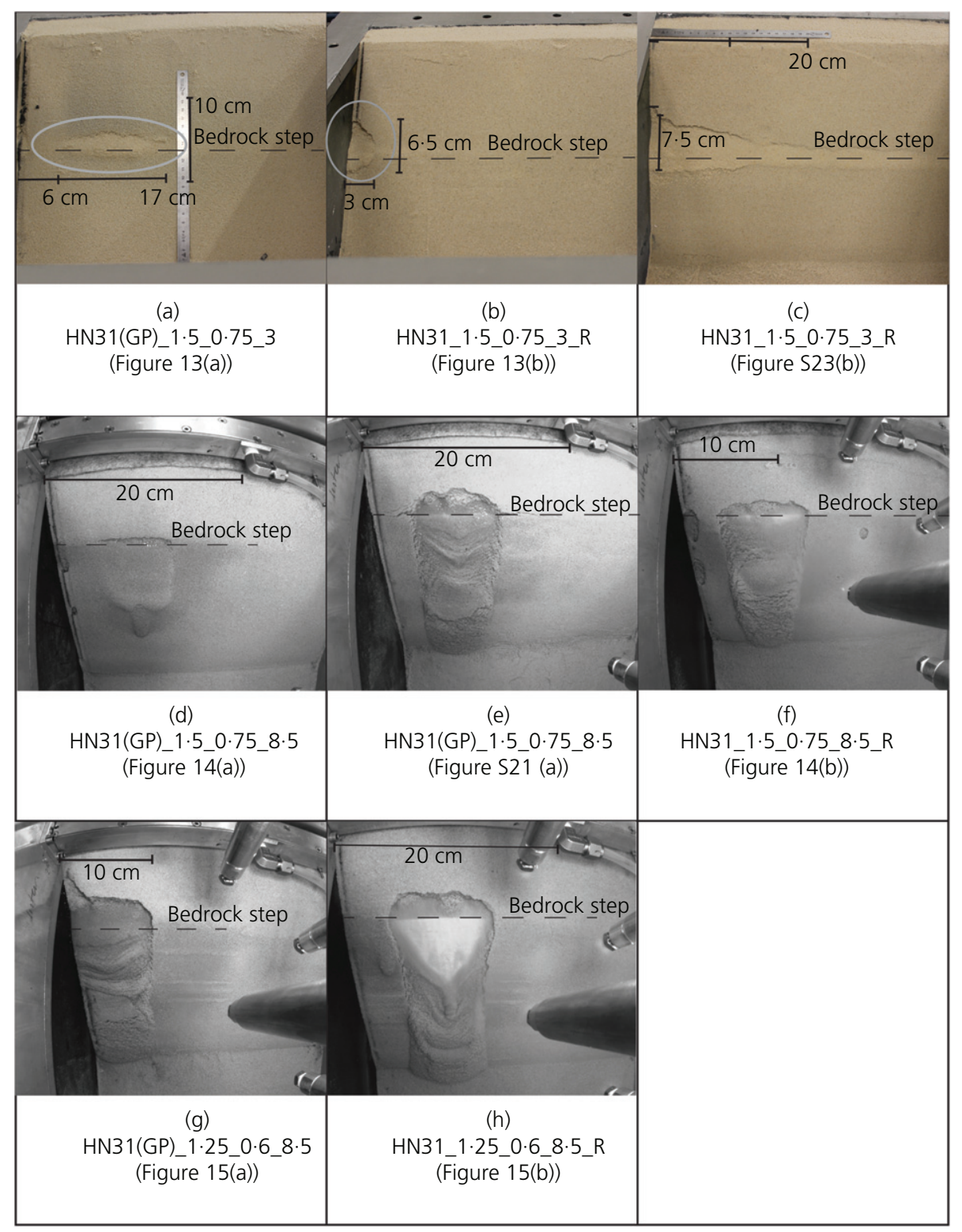

Figure 11. Physical modelling photographs captured after slope failure. (a) Test 2.b, (b) test 3.b, (c), and during failure: test 4.b, (d) test 1.a, (e) test 1.a proof, $(\mathrm{f})$ test 5.a, $(\mathrm{g})$ test 7.a and (h) test 8.a 
International Journal of Physical Modelling in Geotechnics Volume 20 Issue 4
Modelling of landslides in a scree slope induced by groundwater and rainfall

Lucas, Herzog, Iten et al. side (1 $g$ direction). Test 3.b (Figure 13(b)) combined rain of $613 \mathrm{ml} / \mathrm{min}$ equivalent to a rainfall intensity of $142 \mathrm{~mm} / \mathrm{h}$ on the model scale and $2.8 \mathrm{~mm} / \mathrm{h}$ in prototype from four nozzles (see further detail in the online supplementary material) from the last $5 \mathrm{~min}$ of GW flow rate of $1000 \mathrm{ml} / \mathrm{min}$. The slope did not fail surficially, although significant erosion occurred on the PMMA side (Figure 11(b)).

A later test 4.b (see the online supplementary material), with the same model, combined higher rain of $1379 \mathrm{ml} / \mathrm{min}$ equivalent to a rainfall intensity of $215 \mathrm{~mm} / \mathrm{h}$ on the model scale $(4 \cdot 3 \mathrm{~mm} / \mathrm{h}$ prototype), the soil bulged over the top of the step (1500 $\mathrm{ml} / \mathrm{min} \mathrm{GW}$ flow), similar to the failure mechanism in test 2.b (Figure 11(a)), although intense rain mobilised the soil downslope (Figure 11(c)).

Tests 1.a and 5.a (Figure 14) represented the model with the most unfavourable conditions for stability, given the highest and longest bedrock step. The soil exhibited suction initially in test 1.a (Figure 14(a)), which decreased as PWP built up during continuous $\mathrm{GW}$ flow, increasing from 500 to $2000 \mathrm{ml} / \mathrm{min}$. The top PPTs were located upslope of the bedrock step, where the increased PWP was higher with $2-8 \mathrm{kPa}$ on the PMMA side (PPT1) and 1-4 kPa nearer the wall (PPT2). Increased PWP at mid-slope and the bottom of the slope were similar with values between 1 and $4 \mathrm{kPa}$.

Failure was initiated at the top of the slope with a GW flow rate of $1500 \mathrm{ml} / \mathrm{min}$, where the water could pond, before flowing up and over the bedrock step. Cracking was observed and the soil volume mobilised was greater than in test 2.b (Figure 11(d)), with run-out occurring later, as the GW flow rate increased to $2000 \mathrm{ml} / \mathrm{min}$. A proof test of the same model was performed with similar results in terms of the type, location and dimension of the failure, which confirms the reproducibility of the phenomena (Figure 11(e)), although the run-out almost reached the bottom of the slope in this case. PWP increase is higher on the PMMA side (PPT1) and varies between 2 and $6 \mathrm{kPa}$ for the PPT at the top, and $1-2 \mathrm{kPa}$ for the mid-slope and downslope locations in test $5 . \mathrm{a}$

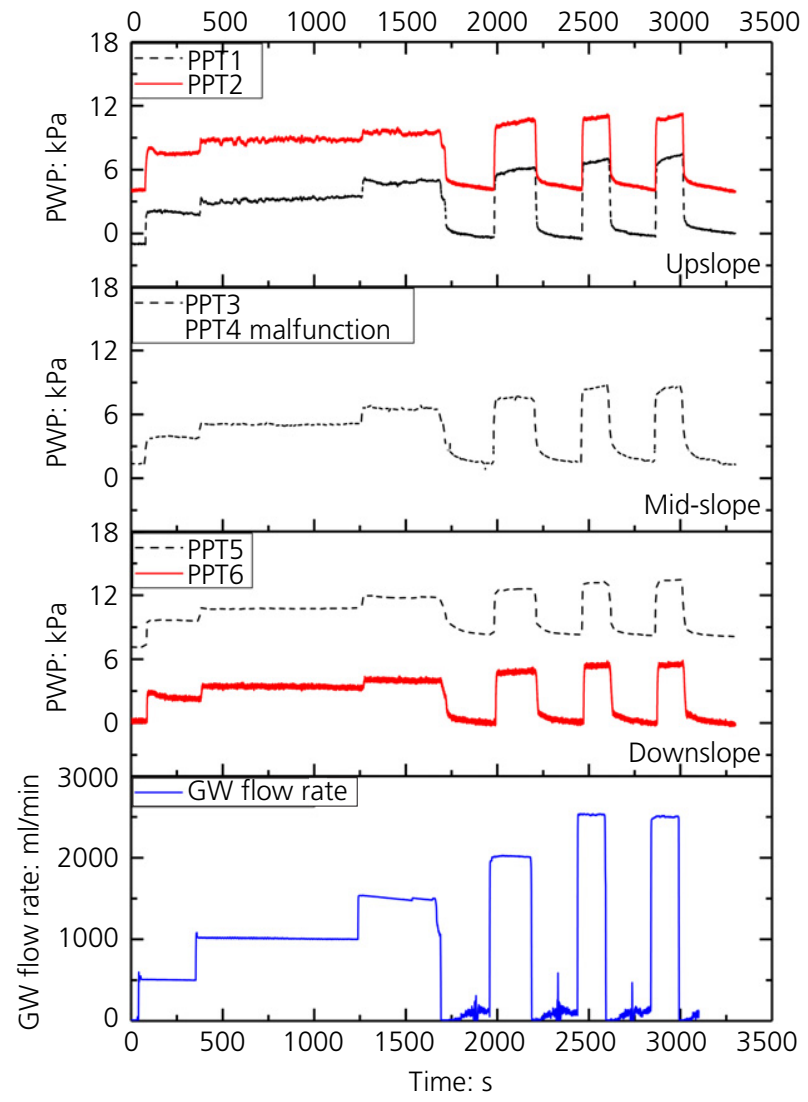

(a)

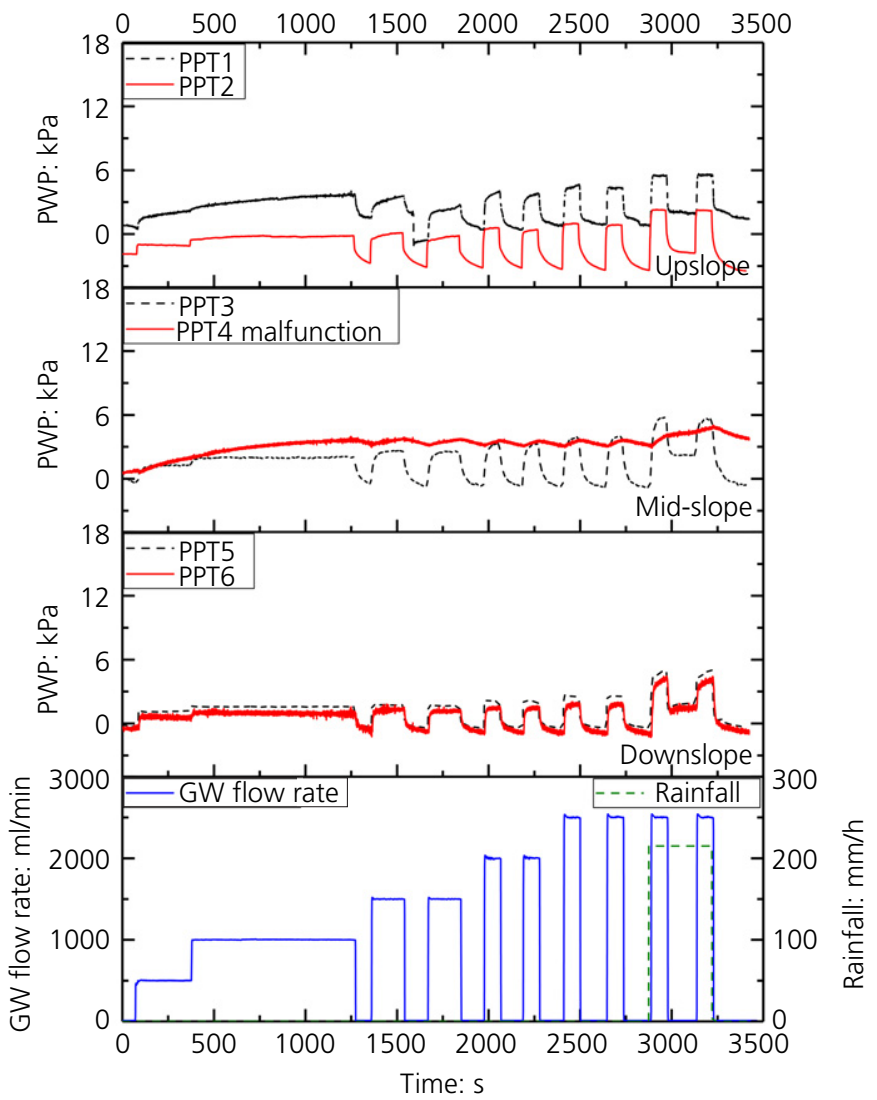

(b)

Figure 12. PWP and GW flow rate plotted against time for tests $1 . \mathrm{b}$ and $6 . \mathrm{b}$, which are identical models of $1.5 \mathrm{~m}$ soil thickness with slope with no bedrock step $(y=0)$ : (a) 1.b HN31_1.5_0_0 under GW flow infiltration and (b) 6.b HN31_1.5_0_0_R GW flow combined with rainfall 
(Figure 14(b)), as well as test 1.a. Failure occurred in test 5.a at GW flow of $1000 \mathrm{ml} / \mathrm{min}$, when adding intense rainfall of $1479 \mathrm{ml} / \mathrm{min}$ (equivalent to $231 \mathrm{~mm} / \mathrm{h}$ at model scale; $4.6 \mathrm{~mm} / \mathrm{h}$ prototype), as expected from test $1 . \mathrm{a}$, which failed after a GW flow rate of $1500 \mathrm{ml} / \mathrm{min}$. Failure was similar to test 1.a and was located upslope of the bedrock step (Figure 11(f)).

Soil thickness of $1.25 \mathrm{~m}$ with a mid-height bedrock step of $y / h=0.6$ and the longest step length $X_{2}=8.5 \mathrm{~m}$ were represented in tests 7.a and 8.a (Figure 15). The increased PWP was similar on both sides and for all elevations, varying between 2.5 and $7.5 \mathrm{kPa}$ at the top of the slope in test 7 .a (Figure 15(a)), reducing to $2 \cdot 5-4.5 \mathrm{kPa}$ at mid-slope and $2-3 \mathrm{kPa}$ for the bottom of the slope. Failure was triggered by a GW flow rate of $2000 \mathrm{ml} / \mathrm{min}$ (Figure 11(g)) with a similar failure mechanism to that described in test 1.a (Figure 14(a)), starting at the junction of bedrock and slope, mobilising one quarter of the width of the slope with a run-out reaching the bottom of the slope. Erosion on the PMMA side probably induced the failed volume to move in this direction.
The model for test 8.a (Figure 15(b)) responded similarly to that for test 7.a, with increased PWP at the top of the slope between 2 and $7.5 \mathrm{kPa}$, with $1-3.5 \mathrm{kPa}$ at mid-slope and $0 \cdot 5-15 \mathrm{kPa}$ at the bottom. This last higher PWP was due to the ponding of water due to GW flow and rainfall of $1479 \mathrm{ml} / \mathrm{min}$ (equivalent to $231 \mathrm{~mm} / \mathrm{h}$ at model scale and $4.6 \mathrm{~mm} / \mathrm{h}$ prototype). Failure happened, as expected, for a GW flow of $1500 \mathrm{ml} / \mathrm{min}$ plus intense rain, initiated at the same location of test 7.a, but more in the centre (no erosion), mobilising the full soil thickness over the step, with run-out that reached the bottom of the slope (Figure 11(h)).

\section{Discussion}

\subsection{Representation of field conditions}

The field ground model was taken as the basis for parametric studies using numerical simulations and centrifuge tests to investigate simplified hydrological conditions, combining GW and rainfall necessary to cause surficial landslides in the models. The geometry and scaled soil (SP-SM) were simplified and a berm was introduced at the base of the slope, to prevent excessive erosion at the toe; nonetheless, it affected failure
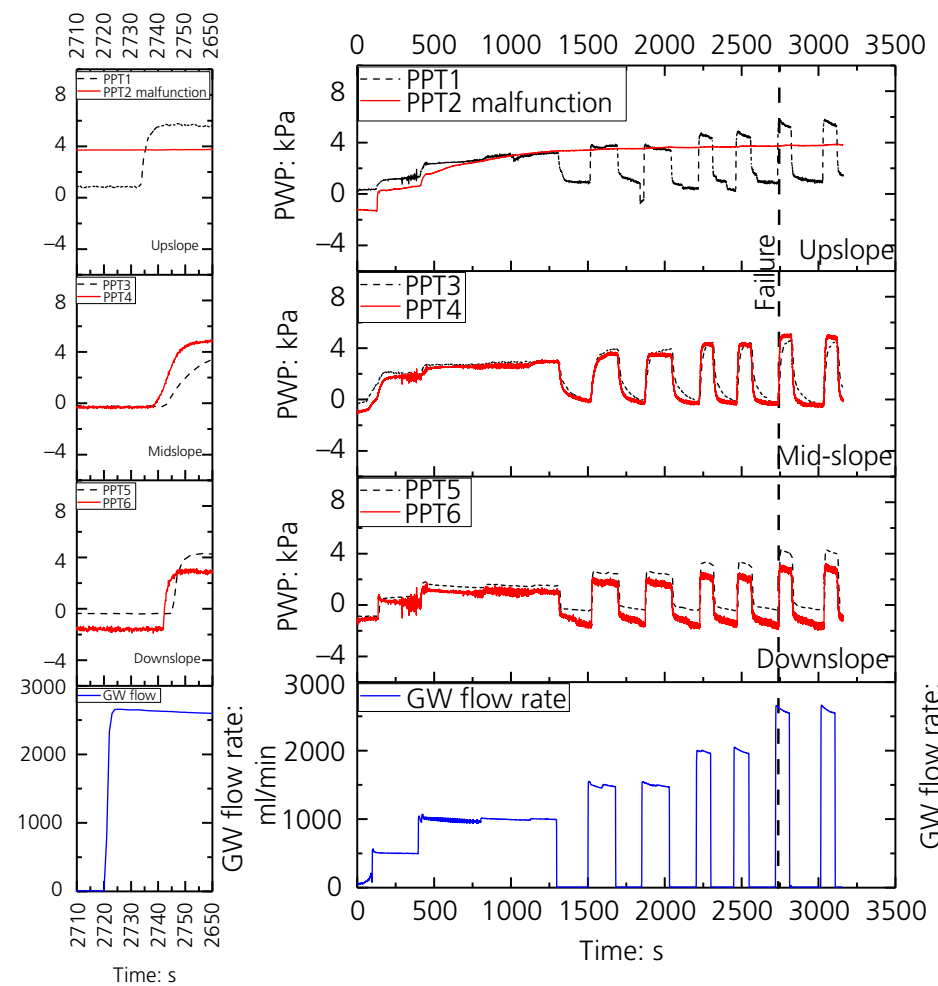

(a)

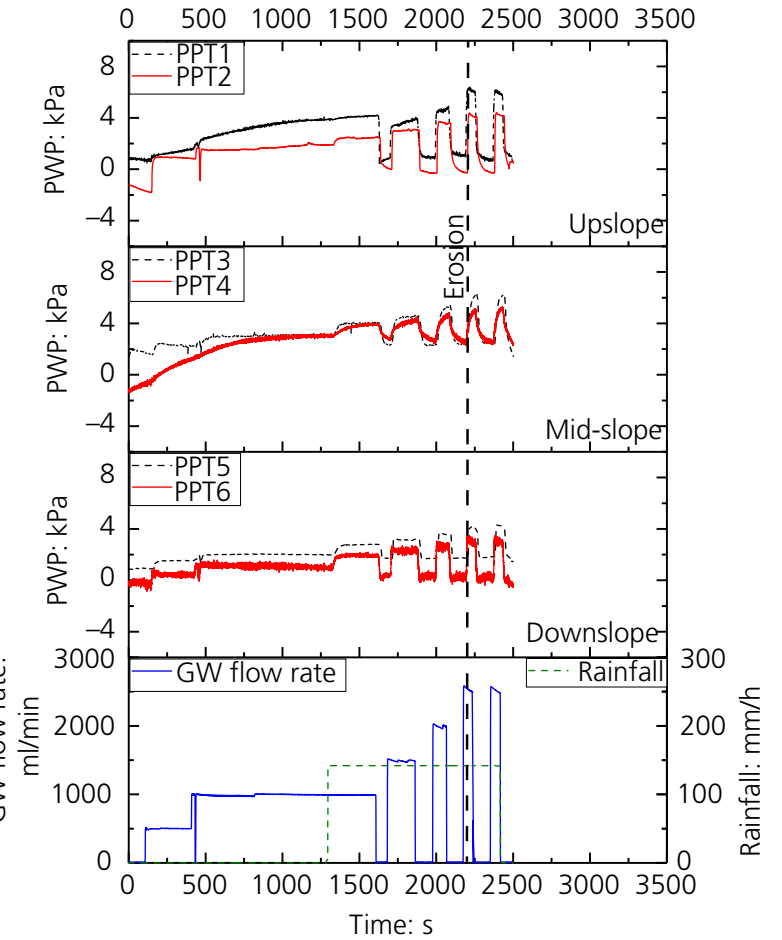

(b)

Figure 13. PWP and GW flow rate plotted against time for identical models with $h=1.5 \mathrm{~m}$, and bedrock step $y / h=0.75$ and with step length $X_{2}=3 \mathrm{~m}$ (prototype) for (a) test 2.b HN31_1.5_0.75_3 (the vertical dashed line shows the time of failure and a zoom figure at the left) and (b) test 3.b HN31_1.5_0.75_3_R 
International Journal of Physical Modelling in Geotechnics Volume 20 Issue 4
Modelling of landslides in a scree slope induced by groundwater and rainfall

Lucas, Herzog, Iten et al. initiation in six out of 11 cases (Figure 6). GW flow was more local in the field, but was applied uniformly across the models, assuming a plane-strain condition.

\subsection{Numerical against physical modelling results}

The numerical modelling results confirmed that a bedrock step increased the potential of a shallow landslide (Section 3). The F.S. decreased as the bedrock step increased in height $(y)$ and length $\left(X_{2}\right)$. Furthermore, an increase in bedrock step length $\left(X_{2}\right)$ had a greater impact than an increase of $y / h$ in decreasing the GW flow rate necessary to cause failure. Slopes without a bedrock step $(y / h=0)$, with high hydraulic gradient, required a larger amount of GW flow/rainfall to induce failure and this would initiate at the location where the water ponds at the berm of the slope. The PWP development, the order of magnitude of the GW flow discharge at failure, the failure mechanism, as well as the effect on the slope stability of the GW flow obtained from the nine centrifuge models, generally agreed with the findings from the numerical modelling. The locations of the failure scarps were similar for comparable models, whereas differences were observed in the extension of the failure mechanism, since the soil is able to run out in the centrifuge test, but this is not possible in the numerical models. An overview of the combined findings, as well as comments on the hypothesis presented in the introduction, is discussed in this section.

\subsection{Triggering of surficial landslides}

Various bedrock geometries were investigated in numerical models. The slopes were subjected to different GW flow discharge levels. Moreover, the hydrological regime was extended with rainfall in the centrifuge tests. Both modelling types supported the hypothesis that GW flow and rainfall infiltration increase the PWP, reduce suction and increase the potential for surficial instabilities and that this is affected by varying soil thickness and bedrock step geometry. Antecedent GW flow combined with intense rainfall in centrifuge tests led to both bottom-up and top-down saturation modes (Kienzler, 2007), which decreased suction and increased the unsaturated hydraulic conductivity of the soil. This promoted faster rainfall infiltration (Elia et al., 2017; $\mathrm{Ng}$ and Shi, 1998), leading to a more sudden and greater increase of PWP, which was distributed along the

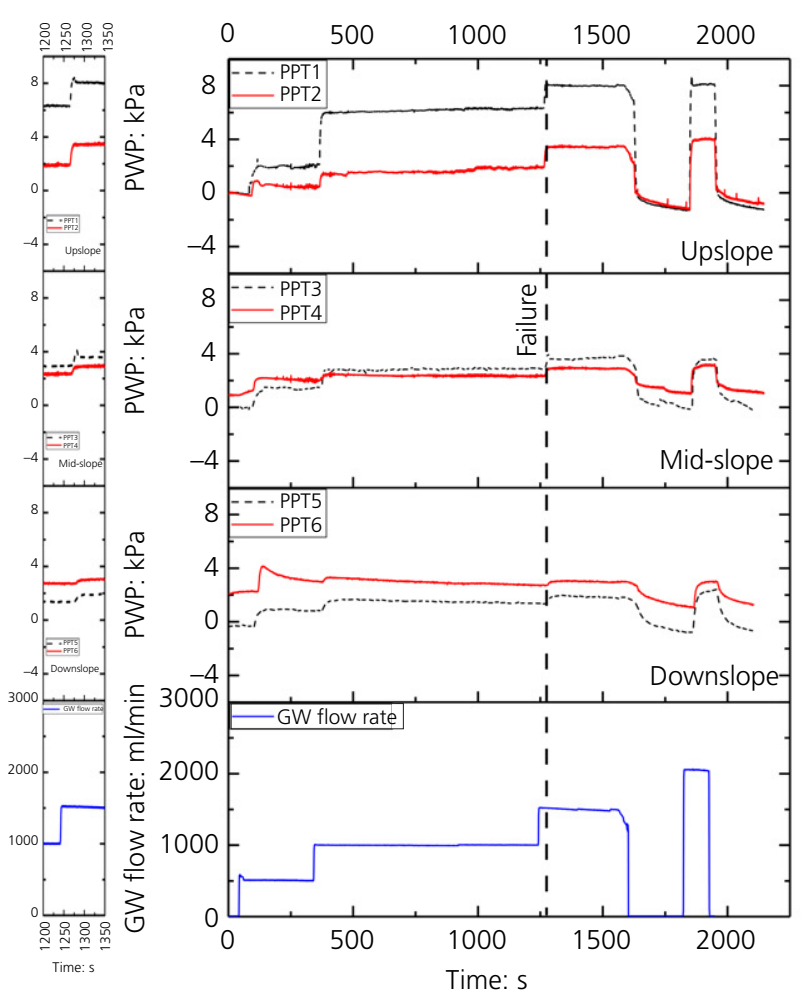

(a)
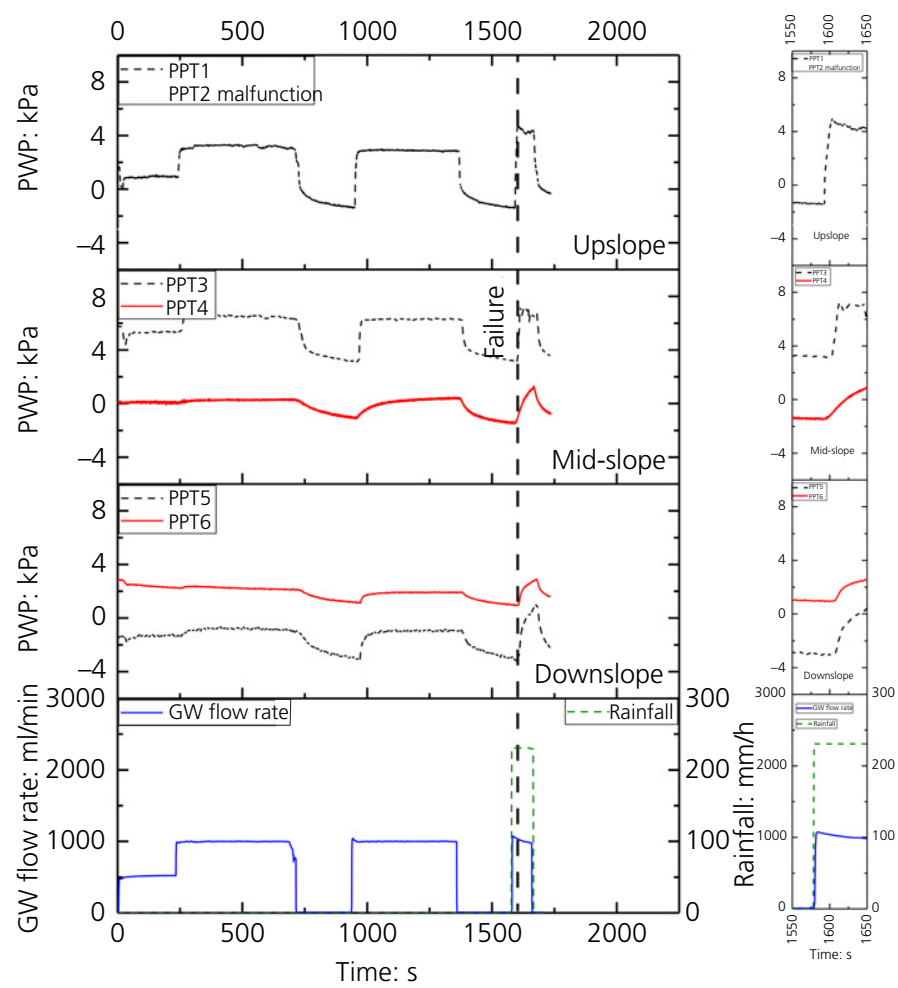

(b)

Figure 14. PWP and GW flow rate plotted against time for identical models with $h=1.5 \mathrm{~m}$ soil thickness, bedrock step $y / h=0.75 \mathrm{with}$ a step length $X_{2}=8.5 \mathrm{~m}$ (prototype). A black dashed line shows the time of failure. (a) Test 1.a HN31_1.5_0.75_8.5 and (b) test 5.a HN31_1.5_0.75_8.5_R. A zoom of the PWP during failure is shown for each case at left and right, respectively 


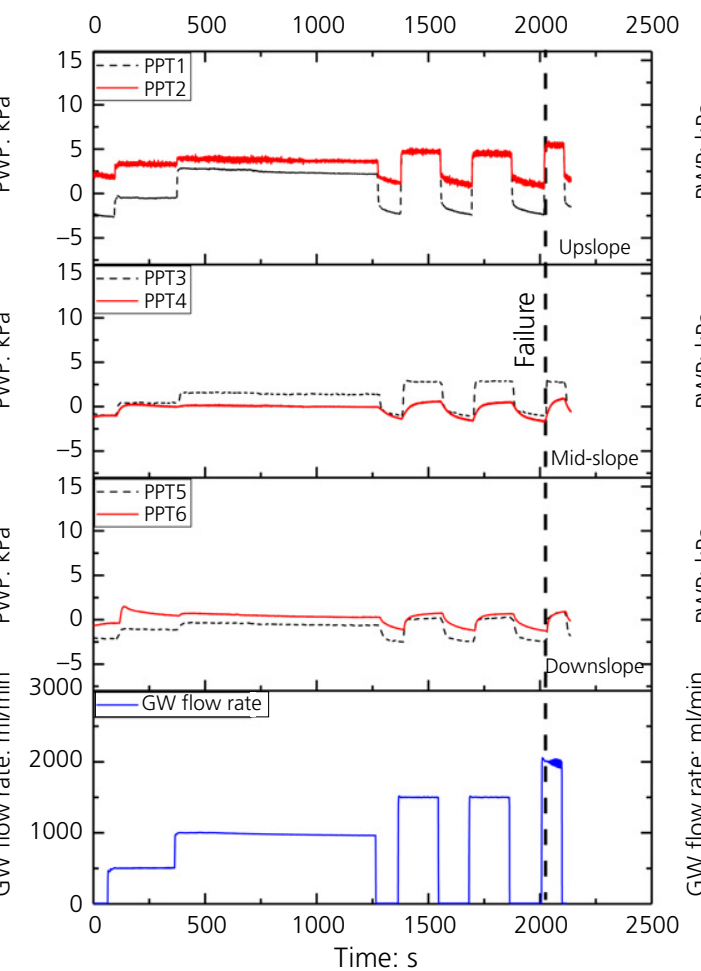

(a)

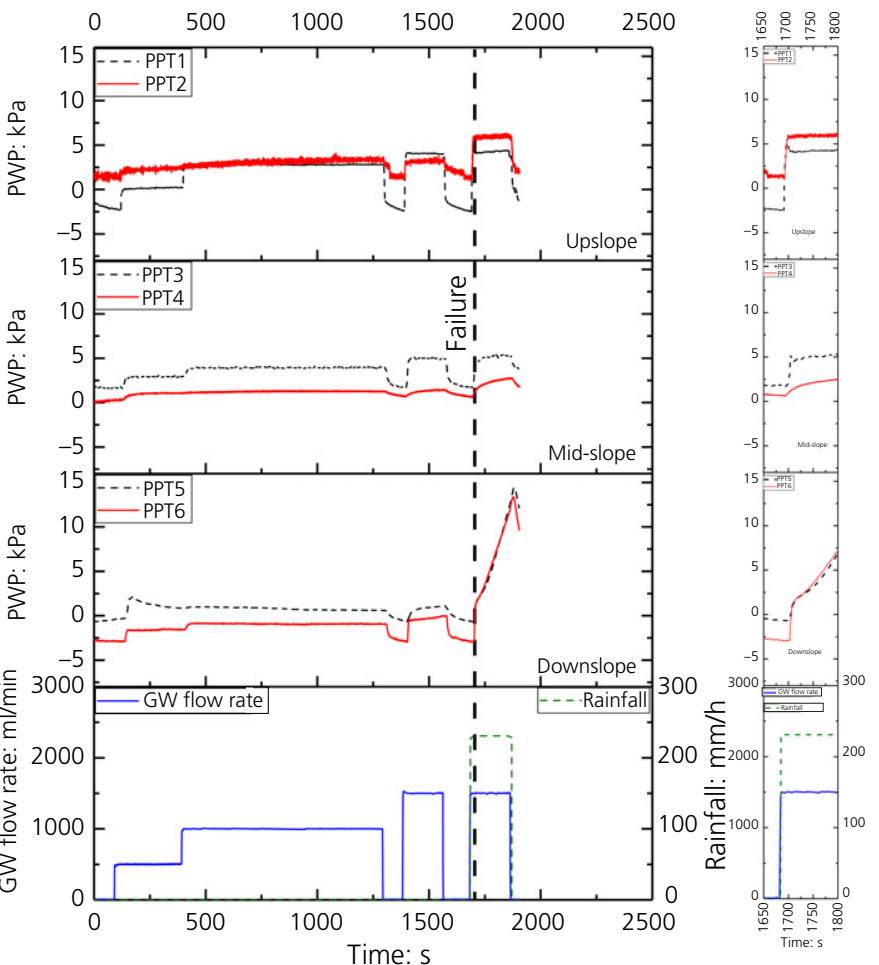

(b)

Figure 15. PWP and GW flow rate plotted against time for identical models with $h=1.25 \mathrm{~m}$, and bedrock step $y / h=0.6$ with step length $X_{2}=8.5 \mathrm{~m}$ (prototype). A vertical dashed line shows the time of failure. (a) Test 7.a HN31_1.25_0.6_8.5 and (b) test 8.a HN31_1.25_0.6_8.5_R. A zoom of the PWP during failure is shown for each case at left and right, respectively

slope, especially over the bedrock step. This increases the hazard considerably (Askarinejad et al., 2018).

Variation in bedrock geometry with higher and longer bedrock steps, and less soil thickness would reduce the GW flow rate required at failure (Askarinejad et al., 2014b). Excess PWPs were dissipated quickly in physical models when the discontinuous GW flow applied was at a lower rate than the GW flow rate required at failure (Figures $12-15$ ). This was also observed in measurements of VWC during field monitoring (Lucas et al., 2017).

A critical intensity of GW flow to trigger surficial failure, for each slope geometry at prototype scale (50g) (Figure 16), could be estimated from numerical simulations. An expected water table was predicted (Figure 6). This critical flow was then converted using centrifugal scaling relationships (Askarinejad, 2013; Dell'Avanzi and Zornberg, 2002).

The magnitude of GW flow required to cause a slope failure for various shapes of the bedrock, predicted using numerical and centrifuge modelling, is summarised in Figure 16. The results from numerical models show that the height of the

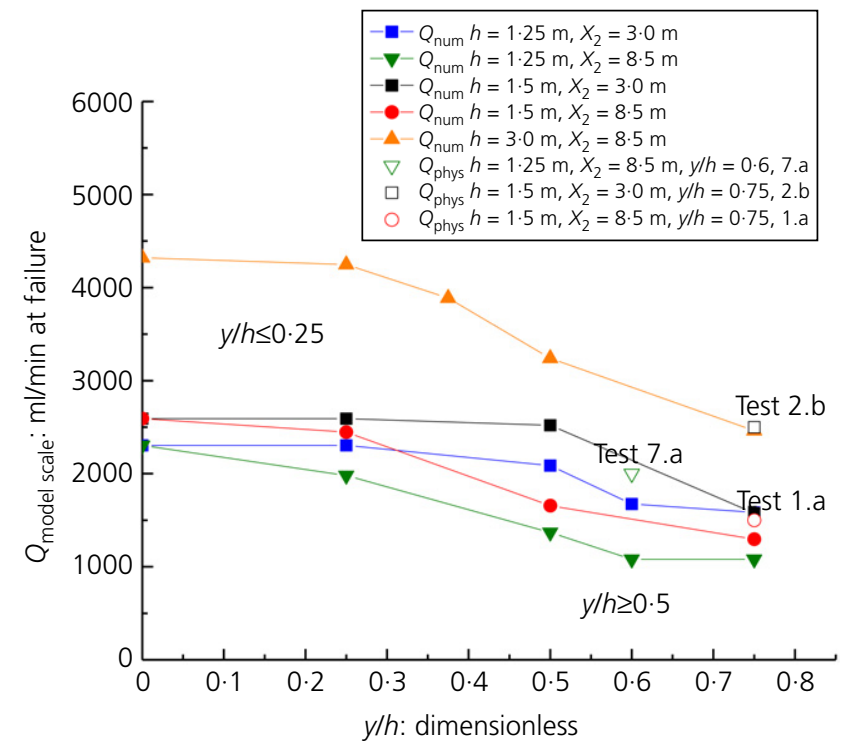

Figure 16. GW flow rate $Q_{\text {num }}$ predicted by numerical modelling for the scaled centrifuge model to trigger a surficial failure at $50 \mathrm{~g}$ level for different heights of bedrock step and GW $Q_{\text {phys }}$ flow rate recorded at failure in centrifuge testing against $y / h$ 
Table 3. Comparison of GW flow rates calculated/observed to cause a slope failure

\begin{tabular}{|llclcc} 
Case & Numerical test & GW flow rate numerical: $\mathbf{m l} / \mathbf{m i n}$ & Physical test & GW flow rate physical: $\mathbf{m l} / \mathbf{m i n}$ & Difference factor: \% \\
\hline 1 & GP_1.5_0.75_8.5 & $1296 \cdot 0$ & $1 . a$ & $1500 \cdot 0$ & $15 \cdot 7$ \\
2 & GP_1.5_0.75_3.0 & $1576 \cdot 8$ & $2 . b$ & $2500 \cdot 0$ & $58 \cdot 5$ \\
3 & GP_1.25_0.6_3.0 & 1584.0 & $7 . a$ & $2000 \cdot 0$ & $26 \cdot 3$
\end{tabular}

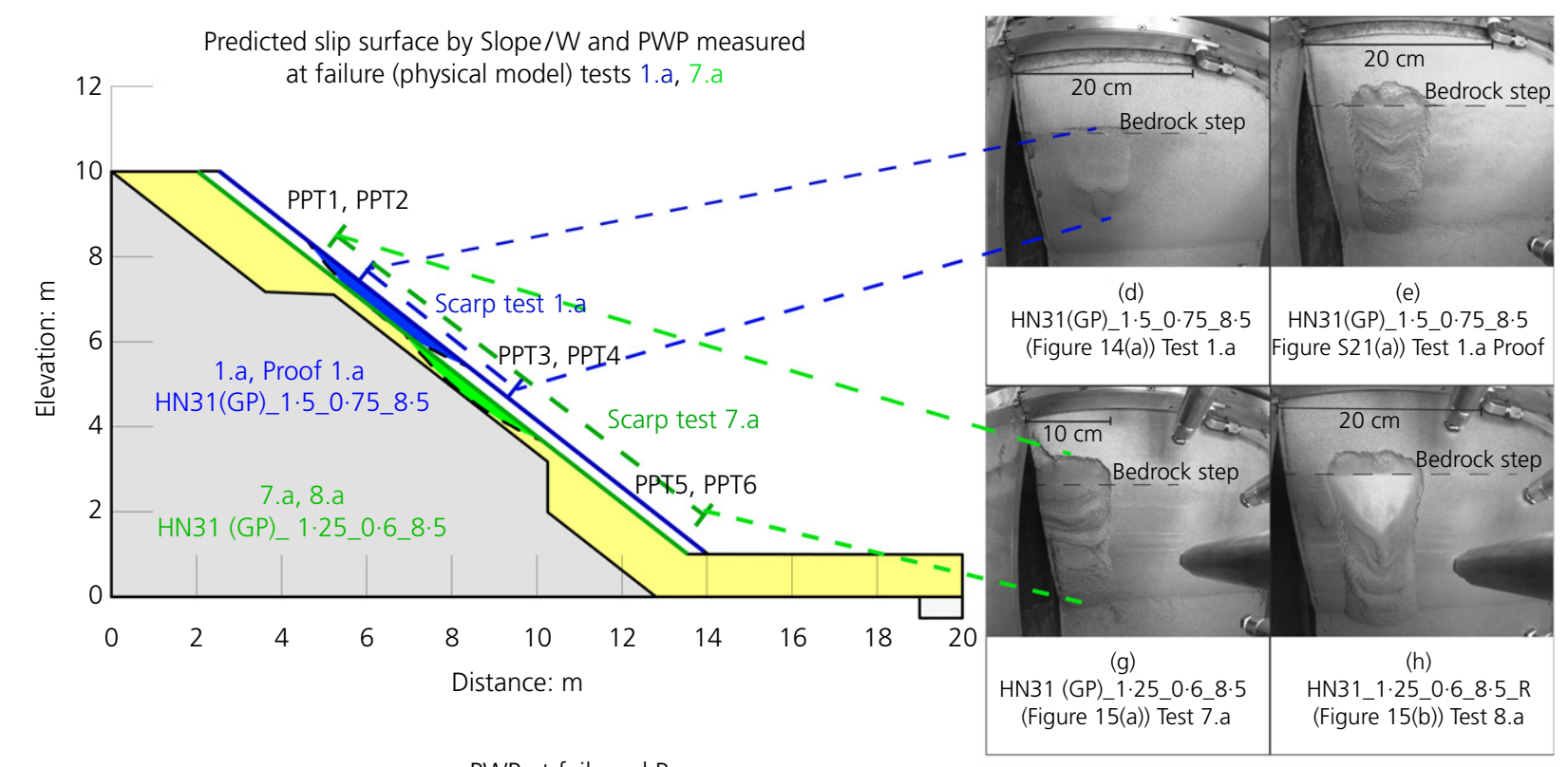

\begin{tabular}{|c|c|c|c|c|c|c|}
\hline & \multicolumn{6}{|c|}{ PWP at failure: $\mathrm{kPa}$} \\
\hline Test & PPT1 & PPT2 & PPT3 & PPT4 & PPT5 & PPT6 \\
\hline Test 1.a & $8 \cdot 3$ & $3 \cdot 4$ & $3 \cdot 8$ & $2 \cdot 8$ & 1.4 & $2 \cdot 7$ \\
\hline Test proof & $5 \cdot 8$ & $2 \cdot 2$ & $8 \cdot 3$ & 1.5 & 1.6 & 4.5 \\
\hline Test 7.a & 5.9 & $5 \cdot 5$ & $-0 \cdot 1$ & $-1 \cdot 2$ & $-2 \cdot 5$ & $-1 \cdot 2$ \\
\hline Test 8.a & $5 \cdot 5$ & $5 \cdot 4$ & 1.7 & 0.7 & -0.6 & $-2 \cdot 8$ \\
\hline
\end{tabular}

Figure 17. Failure slip surface predicted by numerical models (solid fill) $h=1.25 \mathrm{~m}, y / h=0.6, X_{2}=8.5 \mathrm{~m}$ and $h=1.5 \mathrm{~m}, y / h=0.75$, $X_{2}=8.5 \mathrm{~m}$, failure scarp extension from centrifuge tests 1.a, 7.a and PWP measured in centrifuge tests 1.a, proof 1.a, 7.a and 8.a

bedrock step has a major influence on the minimum required hydro-geological discharge to trigger a slope failure; the higher the step, the lower the required GW flow rate to trigger a failure. This observation is valid for all of the bedrock step lengths.

A comparison of the results from centrifuge tests to the numerical modelling results indicates a difference between the two values for the same bedrock geometry (Figure 16, Table 3). The minimum magnitude of $\mathrm{GW}$ discharge to cause a failure predicted by the centrifuge models is generally higher than that calculated from the numerical models (by factors of 1.16 for test $1 . a, 1.59$ for test $2 . b, 1.26$ for test $7 . a$ ). Reasons for this discrepancy could be that the hydromechanical properties of the soil defined for the numerical soil model are not exactly the same as those of the soil used for the centrifuge models. Additionally, the GW flow rate applied in the centrifuge increases by discrete steps $(500,1000$, $1500 \mathrm{ml} / \mathrm{min}$ ).

More specifically, the permeability used for the numerical soil model is expected to be higher than that of the soil used in the centrifuge tests, under comparable states. Furthermore, the 3D shape of the failures in the centrifuge tests also contributes to the slightly more stable behaviour, compared to the assumed 2D plane-strain numerical models, although tension cracking could counter some of these effects.

\subsection{Failure mechanisms}

The extension of the slip surfaces obtained from numerical and physical models agreed for the tests under GW flow and 
showed that failure would be conditioned to step geometry, developing upstream of the bedrock step in the most unfavourable case. Numerical simulations and physical modelling results at failure are shown in Figures 6 and 11, respectively, indicating that the mechanism is initiated where $\mathrm{GW}$ emerges at the ground surface (Figure 17).

If the bedrock step is low, no spring emerges, and failure starts at the junction between the slope and the horizontal berm, mobilising the greatest volumes of soil for the entire test series. This is also dependent on soil depth - for example, Figure 6 cases (a), (b), (e), (i) and (j); however, retrogressive failures could occur in reality when a spring emerges on the slope.

When the soil depth is thicker (case (h)), a local failure has occurred at the bottom of the slope. Progressive failure is expected to follow here too, which would lead to the mobilisation of a larger failure mass, with successive releases at different times.

Figures 11(d)-11(h) and Figures 6(c), 6(g) and 6(k) show that the combination of water table springs directly above the step lead to smaller mobilised volumes and failure above the bedrock step, whereas the other cases 6(f), (d) are somewhat mixed and indicate intermediate failure volumes.

Tension cracks were observed in centrifuge model tests (with GW and GW plus rain) to develop at the crest of the slope, where water accumulated behind the bedrock step. Evidence of partial liquefaction of the soil can be seen in the form of apparently fluidised tongues, showing significant displacement and greater run-out (Figures 11(d), 11(e), 11(f) and 11(h)). Table 4 includes the PWP, effective stresses in the slope at the time of failure as well the excess PWP ratio $\left(R_{\mathrm{u}}=u / \gamma_{z}\right.$, with $u$ is the pore pressure and $\gamma_{z}$ is the total vertical stress) for tests 1.a, 2.b, 5.a, 7.a and 8.a. $R_{\mathrm{u}}$ increases during the PWP build-up phase and reaches 1.0 if liquefaction occurs. The highest values were found for PPTs 3 and 4, in tests 1.a and 2.b, but these were still below $R_{\mathrm{u}}=0 \cdot 6$.

A combination of GW flow plus intense rainfall, for bedrock steps with $y / h>0 \cdot 6$, caused sudden landslides and run-out, which reached the berm (Figures 11(f) and 11(h)). This indicates greater hazard. A longer slope would probably experience either a local failure with multiple progressive failures, as expected in Figure 6(h), or a much longer translational mechanism that would destabilise a greater volume of debris on the slope.

\section{Summary and conclusions}

A combination of physical and numerical modelling using a prototype ground model of a steep scree slope, which integrated together field monitoring data and soil characterisation from previous studies, has exposed likely mechanisms of failure and how these are triggered. Each simulation method can complement one another so that the following statements can be made about the landslide hazard.

Prediction of the behaviour of unsaturated granular material in steep slopes subjected to hydraulic

Table 4. Effective stress at failure determined at the locations of PPTs 1-6: centrifuge models HN31_1.5_0.75_8.5 (test 1.a), HN31_1.5_0.75_3 (test 2.b), HN31_1.5_0.75_8.5_R (test 5.a), HN31_1.25_0.6_3 (test 7.a) and HN31_1.25_0.6_8.5_R (test 8.a)

\begin{tabular}{|c|c|c|c|c|c|c|c|}
\hline & & \multicolumn{6}{|c|}{ PPT } \\
\hline & & 1 & 2 & 3 & 4 & 5 & 6 \\
\hline \multirow[t]{2}{*}{$\sigma_{\mathrm{v}}\left(Y=17 \mathrm{kN} / \mathrm{m}^{3}\right): \mathrm{kPa}$} & 1.a, 2.b, 5.a & $32 \cdot 50$ & $32 \cdot 50$ & $8 \cdot 10$ & $8 \cdot 10$ & $32 \cdot 50$ & $32 \cdot 50$ \\
\hline & 7.a, 8.a & $27 \cdot 00$ & $27 \cdot 00$ & $10 \cdot 80$ & $10 \cdot 80$ & $27 \cdot 00$ & $27 \cdot 00$ \\
\hline \multirow[t]{5}{*}{$u: \mathrm{kPa}$} & 1.a & $8 \cdot 39$ & $3 \cdot 46$ & $3 \cdot 86$ & $2 \cdot 83$ & 1.40 & $2 \cdot 72$ \\
\hline & 2.b & $5 \cdot 72$ & - & $2 \cdot 72$ & $4 \cdot 74$ & $4 \cdot 24$ & 3.08 \\
\hline & 5.a & 4.95 & - & $3 \cdot 74$ & -0.94 & $-3 \cdot 01$ & 0.98 \\
\hline & 7.a & $5 \cdot 97$ & $5 \cdot 52$ & -0.05 & $-1 \cdot 26$ & $-2 \cdot 50$ & $-1 \cdot 26$ \\
\hline & 8.a & $5 \cdot 55$ & $5 \cdot 48$ & $1 \cdot 70$ & 0.79 & -0.68 & $-2 \cdot 89$ \\
\hline \multirow[t]{5}{*}{$\sigma_{\mathrm{v}}^{\prime}: \mathrm{kPa}$} & 1.a & $24 \cdot 11$ & $29 \cdot 04$ & $4 \cdot 24$ & $5 \cdot 27$ & $31 \cdot 10$ & $29 \cdot 78$ \\
\hline & 2.b & $26 \cdot 78$ & - & $5 \cdot 38$ & $3 \cdot 36$ & $28 \cdot 26$ & $29 \cdot 42$ \\
\hline & 5.a & $27 \cdot 55$ & - & $4 \cdot 36$ & $9 \cdot 04$ & $35 \cdot 51$ & $31 \cdot 52$ \\
\hline & 7.a & 21.03 & $21 \cdot 48$ & $10 \cdot 85$ & $12 \cdot 06$ & $29 \cdot 50$ & $28 \cdot 26$ \\
\hline & 8.a & $21 \cdot 45$ & $21 \cdot 52$ & $9 \cdot 10$ & $10 \cdot 01$ & $27 \cdot 68$ & $29 \cdot 89$ \\
\hline \multirow[t]{5}{*}{$R_{\mathrm{u}}:$ dimensionless } & 1. $a$ & 0.26 & $0 \cdot 11$ & 0.48 & $0 \cdot 35$ & 0.04 & 0.08 \\
\hline & 2.b & $0 \cdot 18$ & - & 0.34 & 0.59 & 0.13 & 0.09 \\
\hline & 5.a & $0 \cdot 15$ & - & 0.46 & $<0$ & $<0$ & 0.03 \\
\hline & 7.a & 0.22 & $0 \cdot 20$ & 0.00 & $<0$ & $<0$ & $<0$ \\
\hline & 8.a & $0 \cdot 21$ & $0 \cdot 20$ & 0.16 & 0.07 & $<0$ & $<0$ \\
\hline
\end{tabular}


perturbations and their mechanical interactions with the underlying bedrock using numerical simulations requires a rigorous hydro-mechanical coupled analysis, accompanied by various assumptions and simplifications regarding the material constitutive model and input parameters. Moreover, features such as the failure timing, run-out extent and 3D effects cannot be readily predicted, numerically. Therefore, an advanced, state-of-the-art physical modelling technique was used to study the impacts of rain and GW flow, coupled with the shape of the bedrock, on the response of the slope. The observations from the physical modelling were supported using the simplified uncoupled hydro (Seep/W) and mechanical (LEM: Slope/W) numerical modelling.

- Numerical simulation was useful in studying a wide variety of cases and helped select the worst-case scenarios to be investigated further, and quantified, using centrifuge modelling. Different types of bedrock geometry and soil thicknesses, under combined effects of GW flow and rainfall, were simulated in some of the physical models. A steady-state condition for the hydraulic processes was assumed in the numerical models and the results of pore pressure distribution were applied in a $2 \mathrm{D}$ limit equilibrium stability analysis to provide a prediction for the failure location and volume.

- Centrifuge tests were used to verify numerical results, and provided insights into the development of PWP in the scree slopes subjected to GW flow and rainfall, as a function of time. Location and triggering of the shallow failures were monitored in the centrifuge tests and detailed features of the extent and timing of tension cracking and displacement regime of the mobilised mass were recorded. The results of the centrifuge tests in terms of the thresholds for GW flow discharge for the triggering of a landslide, as well as the shape and location of the failure surfaces, were compared to those derived from numerical modelling.

- Results from both approaches supported the hypothesis that, under similar methodological and hydrological boundary conditions, slopes with no steps in the bedrock are more stable than slopes with shallow bedrock combined with a bedrock step, and the larger the step, the lower the flow rate required to cause the slope failure.

- The GSD of the soil used in the centrifuge tests differed from that of the field, due to the limitations imposed by the scale effects. Therefore, the exact values of the rain intensity, and GW flow discharge leading to instabilities cannot be directly compared with the field data. Moreover, it should be mentioned that these investigations were done as parametric studies and naturally, the geometrical parameters of the steps in the bedrock were extremely idealised in the centrifuge and numerical models, compared to the field conditions. Therefore, the centrifuge test results cannot be directly used as class A prediction tools for the field measurements, although they can be applied to define the potentially critical combinations of the bedrock shape and hydraulic input.

- The landslide potential of a slope subjected to a hydraulic regime of GW flow and or rainfall increases when water can pond uphill over higher and longer bedrock steps. Ponding of water locally increases the PWP in the soil mass and subsequently results in a reduction of the effective stress and hence the shear strength, leading to a shallow landslide. However, it was observed that these landslides are generally smaller in volume and have less run-out extent compared to those that are triggered in 'long' slopes with no steps in the bedrock. However, the hydraulic triggering threshold for a slope with no bedrock step is generally higher than that of a slope with a stepped bedrock under similar conditions.

\subsection{Practical relevance and potential applications}

The hypothesis presented in this study is based on observations and measurements collected from a steep scree slope, for a period of 3 years. The ground model has been designed as a prototype, based on geophysical measurements and laboratory testing. The results from this study can be used as a reference to address failure mechanisms in steep gravelly slopes that are under the influence of seasonal precipitation and hydrogeological changes. The challenges and solutions presented here, especially for the physical modelling of landslides using a drum centrifuge, could be relevant for future studies of complex interactive hydro-mechanical processes leading to mass movements.

\section{Acknowledgements}

The authors are most grateful for the funding from the SNF Project number 200021_144326/1 and Canton Valais, together with the Councils of Agarn and Leuk. The project also contributed to the TRAMM2 programme of the ETH Competence Centre of Environmental Sustainability. Furthermore, the authors acknowledge, in particular, the support and advice from Professor Dr. Andy Take, Kerstin Fankhauser, Ernst Bleiker, Reto Grob, Dr. Brian McArdell and Dr. Mario Sartori. They are also grateful to the reviewers for their constructive comments and valuable suggestions, which have helped them improve this paper.

\section{REFERENCES}

Alber S (2017) Investigation of $3 D$ Printed Geomaterials. Master thesis, IGT, ETH Zurich, Zurich, Switzerland.

Askarinejad A (2013) Failure Mechanisms in Unsaturated Silty Sand Slopes Triggered by Rainfall. Doctoral thesis, 
International Journal of Physical Modelling in Geotechnics Volume 20 issue 4
Modelling of landslides in a scree slope induced by groundwater and rainfall

Lucas, Herzog, Iten et al.
ETH Zurich, Zurich, Switzerland, https://doi.org/10.3929/ ethz-a-010002526.

Askarinejad A, Laue J, Zweidler A et al. (2012) Physical modelling of rainfall induced landslides under controlled climatic conditions. In Proceedings of the Conference Eurofuge 2012, Delft, Netherlands. Delft University of Technology and Deltares, Delft, Netherlands, CD-ROM

Askarinejad A, Beck A and Springman SM (2014a) Scaling law of static liquefaction mechanism in a geocentrifuge and corresponding hydromechanical characterization of an unsaturated silty sand having a viscous pore fluid. Canadian Geotechnical Journal 52(6): 708-720, https://doi.org/10.1139/ cgj-2014-0237.

Askarinejad A, Laue J and Springman SM (2014b) Effect of bedrock shape and drainage properties on the stability of slopes. In ICPMG2014 - Physical Modelling in Geotechnics (Gaudin C and White D (eds)). Taylor \& Francis, London, UK, vol. 2, pp. 1211-1217.

Askarinejad A, Akca D and Springman SM (2018) Precursors of instability in a natural slope due to rainfall: a full-scale experiment. Landslides 15(9): 1745-1759, https://doi.org/10.1007/ s10346-018-0994-0.

Bryant SK, Take WA, Bowman ET and Millen MDL (2015) Physical and numerical modelling of dry granular flows under Coriolis conditions. Géotechnique 65(3): 188-200, https://doi.org/10.1680/ geot.13.P.208

Caicedo B and Thorel L (2014) Centrifuge modelling of unsaturated soils. Journal of Geo-Engineering Sciences 2(1-2): 83-103.

Carrier III WD (2003) Goodbye, Hazen; hello, Kozeny-Carman. Journal of Geotechnical and Geoenvironmental Engineering 129(11) 1054-1056.

Craig WH (2014) Modelling slope failures by 'gravity turn-on'. In ICPMG2014 - Physical Modelling in Geotechnics (Gaudin C and White D (eds)). Taylor \& Francis, London, UK, pp. 1203-1209.

Dell'Avanzi E and Zornberg JG (2002) Scale factors for centrifuge modeling of unsaturated flow. In Proceedings of the Third International Conference on Unsaturated Soils UNSAT 2002, Recife, Brazil, March 10-13 (Jucá JFT, de Campos T and Marinho F (eds)). Balkema, Lisse, the Netherlands, vol. 1, pp. 425-430.

Elia G, Cotecchia F, Pedone G et al. (2017) Numerical modelling of slope-vegetation-atmosphere interaction: an overview. Quarterly Journal of Engineering Geology and Hydrogeology 50(30): 249-270, https://doi.org/10.1144/ qjegh2016-079.

Fankhauser K (2014) Geophysical Slope Characterization Using GPR and ERT in an Active Debris Flow Catchment. Master thesis, EEG, ETH Zurich, Zurich, Switzerland.

Frank F, McArdell BW, Oggier N et al. (2017) Debris-flow modeling at Meretschibach and Bondasca catchments, Switzerland: sensitivity testing of field-data-based entrainment model. Natural Hazards and Earth System Sciences 17(5): 801

Gabus JH, Weidmann M, Burri M and Sartori M (2008a) Feuille 1287 Sierre, Atlas Géologique de la Suisse 1:25’000, Carte 111. Swisstopo, Wabern, Switzerland (in French).

Gabus JH, Weidmann M, Burri M and Sartori M (2008b) Feuille 1287 Sierre, Atlas Géologique de la Suisse 1:25’000, Note Explicative. Swisstopo, Wabern, Switzerland (in French).
Grob R (2015) Measurement of Soil Properties for Gravels in a Scree Slope Using Large Scale Triaxial Testing. Master thesis, IGT, ETH Zurich, Zurich, Switzerland.

Kienzler P (2007) Experimental Study of Subsurface Stormflow Formation. Doctoral thesis, ETH Zurich, Zurich, Switzerland, https://doi.org/10.3929/ethz-a-005477823.

Krahn J (2004a) Seepage Modelling with SEEP/W: An Engineering Methodology. GEO-SLOPE International Ltd., Calgary, Alberta, Canada.

Krahn J (2004b) Stability Modelling with SLOPE/W: An Engineering Methodology. GEO-SLOPE/W International Ltd., Calgary, Alberta, Canada.

Lee YS and Bolton MD (2006) Centrifugal modelling of the landslides triggering mechanism in layered fill slopes. In Physical Modelling in Geotechnics (Ng CWW, Zhang LM and Wang YH (eds)). Taylor \& Francis Group, London, UK, vol. 1, pp. 355-360.

Ling $\mathrm{H}$ and Ling $\mathrm{HI}$ (2012) Centrifuge model simulations of rainfall-induced slope instability. Journal of Geotechnical and Geoenvironmental Engineering 138(9): 1151-1157.

Lucas DR, Fankhauser K and Springman SM (2017) Application of geotechnical and geophysical field measurements in an active alpine environment. Engineering Geology 219: 32-51. https://doi.org/10.1016/j.enggeo.2016.11.018.

Morgenstern NU and Price VE (1965) The analysis of the stability of general slip surfaces. Géotechnique 15(1): 79-93, https://doi.org/ 10.1680/geot.1965.15.1.79.

$\mathrm{Ng}$ CWW and Shi Q (1998) Influence of rainfall intensity and duration on slope stability in unsaturated soils. Quarterly Journal of Engineering Geology and Hydrogeology 31(2): 105-113.

Oggier NC (2011) Simulierung von Murgängen mit RAMMS am Beispiel des Meretschibachs. Master thesis, ETH Zürich und Forschungsanstalt für Wald Schnee und Landschaft (WSL), Zurich, Switzerland (in German).

Park DS (2013) The effect of radial G-field on the centrifuge modelling. In ICPMG2014 - Physical Modelling in Geotechnics (Gaudin C and White D (eds)). Taylor \& Francis, London, UK, pp. $385-390$

Schofield AN (1978) Use of centrifugal model testing to assess slope stability. Canadian Geotechnical Journal 15(1): $14-31$.

Schofield AN (1980) Cambridge geotechnical centrifuge operations. Géotechnique 30(3): 227-268, https://doi.org/10.1680/ geot.1980.30.3.227.

Springman SM, Laue J, Boyle R, White J and Zweidler A (2001) The ETH Zurich geotechnical drum centrifuge. International Journal of Physical Modelling in Geotechnics 1(1): 59-70, https://doi.org/10.1680/ijpmg.2001.010107.

Springman SM, Jommi C and Teysseire P (2003) Instabilities on moraine slopes induced by loss of suction: a case history. Géotechnique 53(1): $3-10$.

Springman SM, Lucas DR, Oggier NC et al. (2015) Study of the seasonal response of a scree slope and debris flow catchment in the Swiss Alps. In XVI European Conference on Soil Mechanics and Geotechnical Engineering (XVI ECSMGE 2015) (Winter MG, Smith DM, Eldred PJL and Toll DG (eds)). ICE Publishing, Westminster, London UK. pp. 1897-1902.

Take WA (2014) Physical modelling of instability and flow in loose granular slopes. In ICPMG2014 - Physical Modelling in Geotechnics (Gaudin C and White D (eds)). Taylor \& Francis, London, UK, pp. 113-124. 
International Journal of Physical Modelling in Geotechnics Volume 20 Issue 4
Modelling of landslides in a scree slope induced by groundwater and rainfall

Lucas, Herzog, Iten et al.
Take WA and Beddoe RA (2014) Base liquefaction: a mechanism for shear-induced failure of loose granular slopes. Canadian Geotechnical Journal 51(5): 496-507.

Taylor RE (1995) Geotechnical Centrifuge Technology. CRC Press, London, UK.
Timpong S, Itoh K and Toyosawa Y (2007) Geotechnical centrifuge modelling of slope failure induced by ground water table change. In Landslides and Climate Change (McInnes R, Jackeways J, Fairbank H and Mathie E (eds)). Taylor \& Francis Group, London, UK, pp. 107-112.

\section{How can you contribute?}

To discuss this paper, please email up to 500 words to the editor at journals@ice.org.uk. Your contribution will be forwarded to the author(s) for a reply and, if considered appropriate by the editorial board, it will be published as discussion in a future issue of the journal.

International Journal of Physical Modelling in Geotechnics relies entirely on contributions from the civil engineering profession (and allied disciplines). Information about how to submit your paper online is available at www.

icevirtuallibrary.com/page/authors, where you will also find detailed author guidelines. 